\title{
Photoselective vaporization of the prostate for the treatment of benign prostatic hyperplasia
}

\author{
Tania Stafinski, MSc; ${ }^{*}$ Devidas Menon, PhD, MHSA; ${ }^{*}$ Kevin Harris, RN, MPH; ${ }^{\dagger}$ Gary Gray MD, MSc; ${ }^{\neq}$ \\ Gian Jhangri, MSc*
}

\begin{abstract}
Objective: In recent years, laser treatments have re-emerged as options for treating benign prostatic hyperplasia (BPH). This paper reviews the safety, efficacy, effectiveness and economics of photoselective vapourization of the prostate (PVP), compared with transurethral resection of the prostate (TURP).
\end{abstract}

Methods: We conducted a comprehensive literature search to identify 14 studies comparing 80 W PVP and TURP. We then reviewed and pooled these studies.

Results: We identified 12 adverse events or complications; rates were similar in both groups. No PVP patient required a blood transfusion; $5 \%-11 \%$ of TURP patients did. PVP patients had a significantly lower likelihood of clot retention. Collectively, the 14 studies led to the conclusion that PVP is a safe procedure. PVP is favourable to TURP regarding length of hospitalization and catheterization times. There were no meaningful differences in operation times, reoperation rates, peak flow rates, postresidual volumes or quality of life scores. Sexual function and prostate specific antigen value changes were similar. Four economic evaluations of PVP and TURP (from Canada, Switzerland, Australia and the United States) concluded that PVP is less costly per case than TURP. Cost differences are attributable to disposables, capital equipment and hospitalization. Based on our analysis of limited Canadian data, the cost of PVP is estimated to be about one-half that of TURP, even after accounting for start-up costs.

Conclusion: The 80 W PVP laser appears to be a viable treatment for $\mathrm{BPH}$. With the recent regulatory approval of the 120 W High Performance System (HPS), an additional option has become available. Therefore, it is anticipated that PVP will soon be considered part of a physician's repertoire for managing $\mathrm{BPH}$.

CUAJ 2008;2(2):1-25

\section{Introduction}

Within the last 5 years, laser technologies have re-emerged as a promising alternative to transurethral resection of the prostate (TURP), which is the current "gold standard" treatment for moderate-to-severe lower urinary tract symptoms (LUTS) related to benign prostatic hyperplasia (BPH) (i.e., clinical BPH). ${ }^{1}$ Such re-emergence has been primarily attributed to the development and introduction of a new laser technique called photoselective vapourization of the prostate (PVP). ${ }^{2}$ Unlike previous laser therapies for BPH, PVP uses a high-powered potassium-titanyl-phosphate (KTP) laser (i.e., the GreenLight PVP, American Medical Systems Inc.,
Minnetonka, Minnesota) that emits light at a wavelength of $532 \mathrm{~nm}$, which falls within the greenlight spectrum. This wavelength is strongly absorbed by hemoglobin but not by water. Therefore, when it is applied to vascularized prostatic tissue, the laser light becomes instantly absorbed by the blood, quickly vapourizing and removing it, creating a prostate cavity with minimal blood loss, postoperative discomfort and hospital stay. ${ }^{3}$

In Canada, clinical BPH affects about 25\% of men over 50 years old and its prevalence increases with age. ${ }^{4}$ Given its chronic nature and the country's growing aging population, $\mathrm{BPH}$ has become recognized as a significant health concern and source of health care expenditures. Awareness of the availability of PVP has generated significant interest among patients, providers and payers, alike. ${ }^{5}$

The purpose of this paper was to review the safety and effectiveness of PVP using the commercially available 80 W KTP laser (Greenlight PV System), compared with TURP, as well as the social and economic considerations involved in providing PVP as part of the publicly funded services for managing $\mathrm{BPH}$.

\section{Methods}

\section{Search for relevant studies}

We completed a search for any published or unpublished clinical studies or economic analyses of PVP appearing in the English language literature before December 2006. Critical terms used to describe BPH and PVP, along with their likely synonyms (e.g., enlarged prostate, GreenLight PVP, etc.), were identified and combined to form a structured search strategy. 
This strategy was subsequently applied to several electronic bibliographic databases to locate relevant published literature. Unpublished or non-peer reviewed information (e.g., conference proceedings, technical papers, government-sponsored reports, etc.) was captured through Internet searches. Key websites were also examined. The electronic search was supplemented by a manual search of the most recent issues of major urological journals and reference lists from retrieved studies. Lastly, 8 specialists (6 in Alberta and 2 in Ontario) were contacted via email or telephone to obtain information on any unpublished or recently completed studies. Corresponding authors of identified studies and urologists who perform PVP and TURP or both were also contacted, along with the manufacturer.

\section{Selection of relevant studies}

Compiled citations were reviewed for relevancy in 2 stages by 2 independent reviewers adhering to Cochrane protocol. ${ }^{6}$ First, titles and available abstracts were screened (stage 1 ). Then, full manuscripts of those deemed potentially relevant were retrieved and assessed using a predefined set of inclusion criteria (stage 2) (Table 1). If doubt over a study's relevancy still remained, further information was sought from the author (2 cases). Where multiple citations from the same investigators appeared to report on the same patient population, only the most recent one (determined by publication date and, when necessary, correspondence with the author) was included. Any discrepancies between reviewers were resolved through discussion. Reviewer consensus was assessed using kappa statistics and found to be excellent $(\kappa=0.79$ stage 1 and $\kappa=0.88$ stage 2$)$.

\section{Synthesis and critical appraisal of selected studies}

Information from each study was systematically extracted by 2 reviewers using a standard, pretested data abstraction form containing elements for assessing the purpose, methods (e.g., setting, number of patients, treatment protocol and outcome measures, etc.) and validity of the results (Table 2$){ }^{8}$ When required, missing data were sought from the corresponding author. Once again, consensus between reviewers was assessed with kappa statistics, with $\kappa=1.0$ indicating perfect agreement.

The quality of each study was scrutinized by 2 reviewers using validated, published critical appraisal guidelines and levels of evidence scales for clinical studies and economic evaluations. ${ }^{9}$ Agreement between reviewers was excellent $(\kappa=0.79)$.

\section{Table 1. Criteria for including studies in the review}

\begin{tabular}{|c|c|c|}
\hline Parameter & Inclusion criteria & Exclusion criteria \\
\hline Study design & $\begin{array}{l}\text { - Randomized or controlled (e.g., pseudorandomized of quasi- } \\
\text { randomized) trials } \\
\text { - Nonrandomized clinical trials } \\
\text { - Retrospective, prospective or concurrent cohort studies } \\
\text { - Case or clinical series }\end{array}$ & \\
\hline Participants & $\begin{array}{l}\text { - Patients diagnosed with moderate-severe LUTS attributable } \\
\text { to BPH who require surgical intervention }\end{array}$ & - Diagnosis of prostate cancer \\
\hline Interventions & - PVP with 80 W KTP laser (Greenlight PV system) & - $\quad$ PVP with $40 \mathrm{~W}$ or $60 \mathrm{~W}$ KTP lasers \\
\hline Comparators & - TURP (not required) & \\
\hline \multicolumn{3}{|l|}{ Outcomes } \\
\hline Primary & $\begin{array}{l}\text { - Increase in peak urinary flow rate } \\
\text { - Decrease in postvoid residual volume } \\
\text { - Decrease (i.e., improvement) in IPPS or AUA score } \\
\text { - Decrease (i.e., improvement) in IPPS Quality of Life score }\end{array}$ & \\
\hline Secondary & - Reduction in prostate volume & \\
\hline Operative & $\begin{array}{l}\text { - Operating time } \\
\text { - Length of hospital stay } \\
\text { - Length of catheterization } \\
\text { - Blood transfusion }\end{array}$ & \\
\hline
\end{tabular}




\section{Data analysis}

Results from individual clinical studies were combined through meta-analyses to generate summary estimates for each outcome of interest. For dichotomous data (e.g., adverse events) pooled relative risks and $95 \%$ confidence intervals were calculated. For continuous data (e.g., peak urinary flow), mean differences and 95\% confidence intervals were pooled and a weighted mean difference was calculated. All statistical analyses were conducted in accordance with intention-totreat principles (i.e., patients were analyzed in the groups to which they were originally allocated regardless of whether or not they received the assigned treatment).

Prior to pooling data, effect sizes among studies were tested for heterogeneity using the $\chi^{2}$ statistic for heterogeneity set at a significance level of $p<0.1$. Only data considered to be sufficiently homogeneous were pooled.

Results from included economic studies were summarized in tabular form and analyzed qualitatively, noting trends or patterns in findings reported across studies.

\section{Development of economic model comparing TURP with PVP in Alberta}

Findings from the review of clinical and economic evidence were used to construct an economic model comparing PVP with TURP in Alberta.
Information on direct and indirect medical costs for TURP and PVP was collected from published literature, Alberta Health and Wellness (for TURP), the manufacturer (for PVP) and hospitals in Ontario where PVP is currently being performed.

\section{Results}

Fifty-four discrete citations were initially identified, 14 of which met the selection criteria: 12 case series, 1 randomized controlled trial (PVP 38 patients, TURP 38 patients) and 1 multicentred cohort study (PVP 64 patients, TURP 37 patients). ${ }^{10-23}$ Collectively, they represented a total of 1376 PVP procedures.

\section{Overall description of included studies}

The 14 studies selected for inclusion in the review are summarized in Table 3. Across included studies, patients'age ranged from 44 to 95 years and prostate sizes varied from small $(17 \mathrm{~mL})$ to large $(336 \mathrm{~mL})$. Most studies followed patients for either 6 months $^{10,16,18,20,21}$ or 12 months. ${ }^{11-15,19,22}$ Only 1 study monitored patients beyond 1 year, reporting outcomes at 24 months. ${ }^{23}$ All but 1 of the studies examined the safety of PVP, noting adverse events and complications that occurred intraoperatively or within the early postoperative period. All of the studies assessed the efficacy of PVP in a similar way - through maximum or peak urinary flow rate, postvoid residual volume and IPSS/AUA-SI

\begin{tabular}{|c|c|}
\hline Parameter & Description of information collected \\
\hline Study design & $\begin{array}{l}\text { - Setting } \\
\text { - Method of randomization, allocation concealment and blinding, where appropriate } \\
\text { - Funding sources }\end{array}$ \\
\hline Participants & $\begin{array}{l}\text { - No. of patients recruited, randomized or assigned to treatment groups (i.e., PVP } \\
\text { or TURP) and included in subsequent analyses } \\
\text { - No. of patients censored (owing to incomplete follow-up or loss to follow-up) } \\
\text { - } \text { Paximum length of follow-up } \\
\text { prostate size, comorbidities and severity of symptoms }\end{array}$ \\
\hline Interventions & $\begin{array}{l}\text { - Actual no. of patients who underwent treatment in each group } \\
\text { - Any protocol violations } \\
\text { - Information on any further therapy received }\end{array}$ \\
\hline Outcomes & $\begin{array}{l}\text { - Changes in peak urinary flow rate, postvoiding residual volume, IPSS or AUA } \\
\text { symptom score, IPSS Quality of Life score and prostate volume } \\
\text { - Operating time, length of hospital stay, length of catheterization and adverse events }\end{array}$ \\
\hline
\end{tabular}




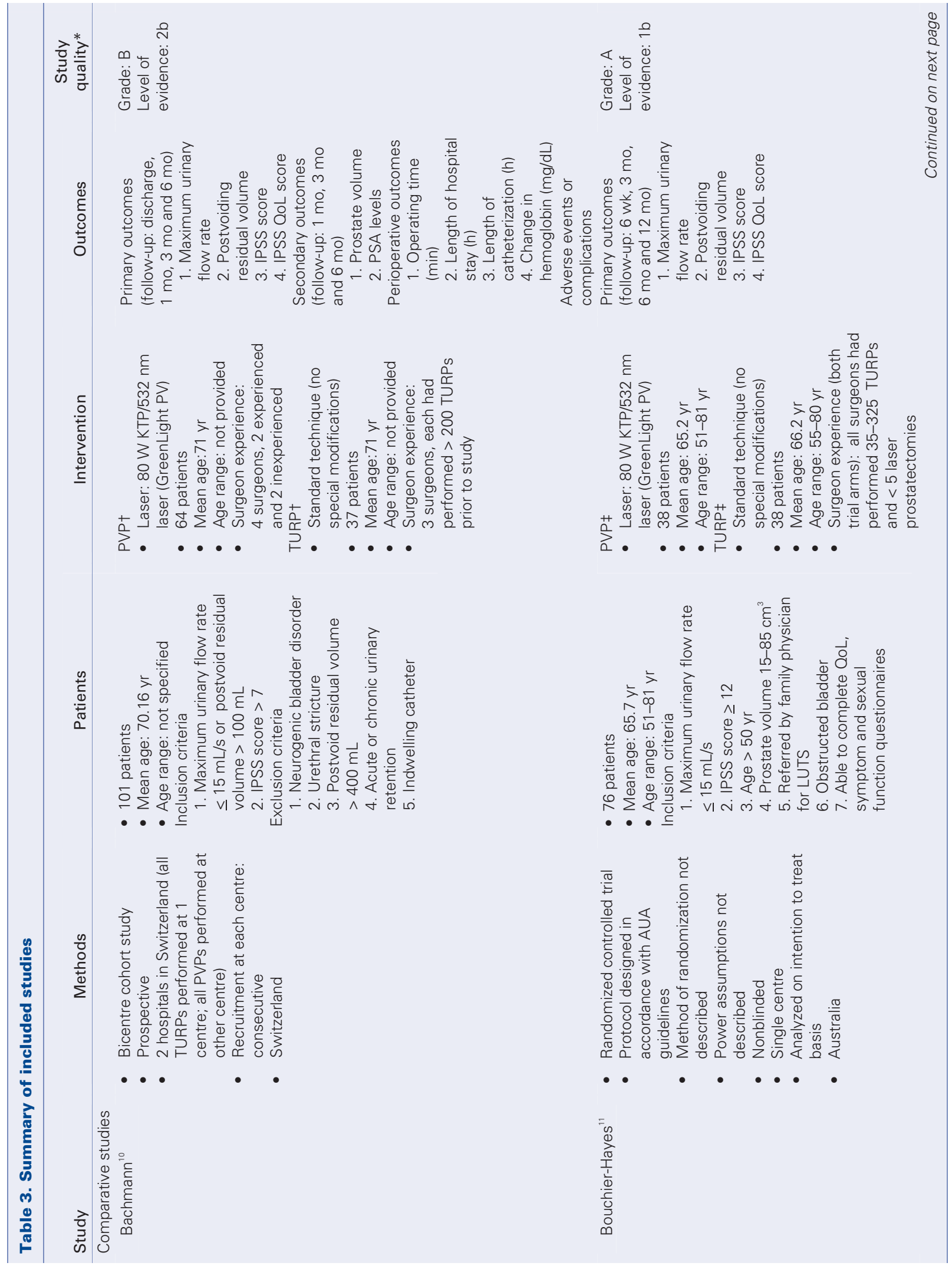




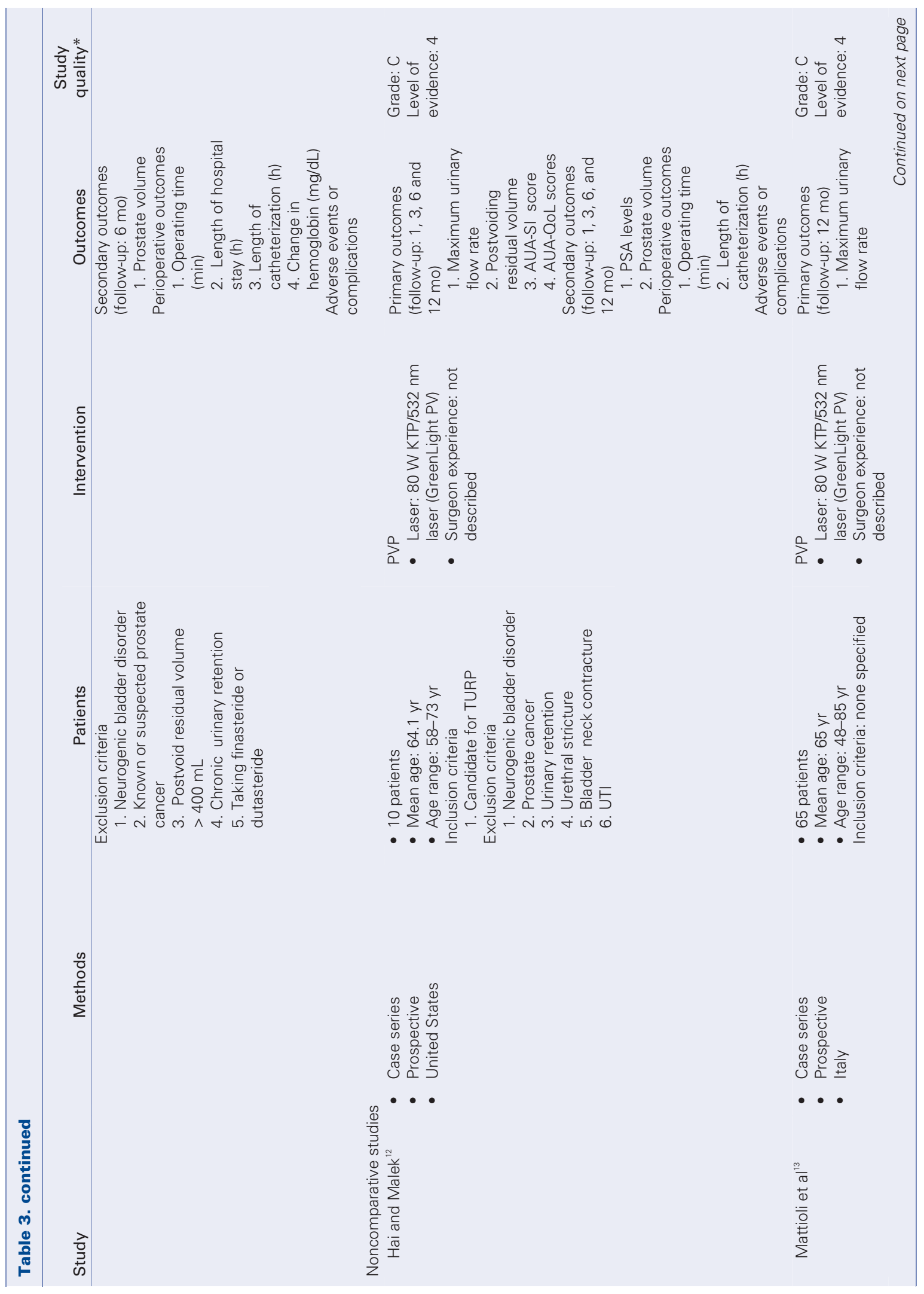




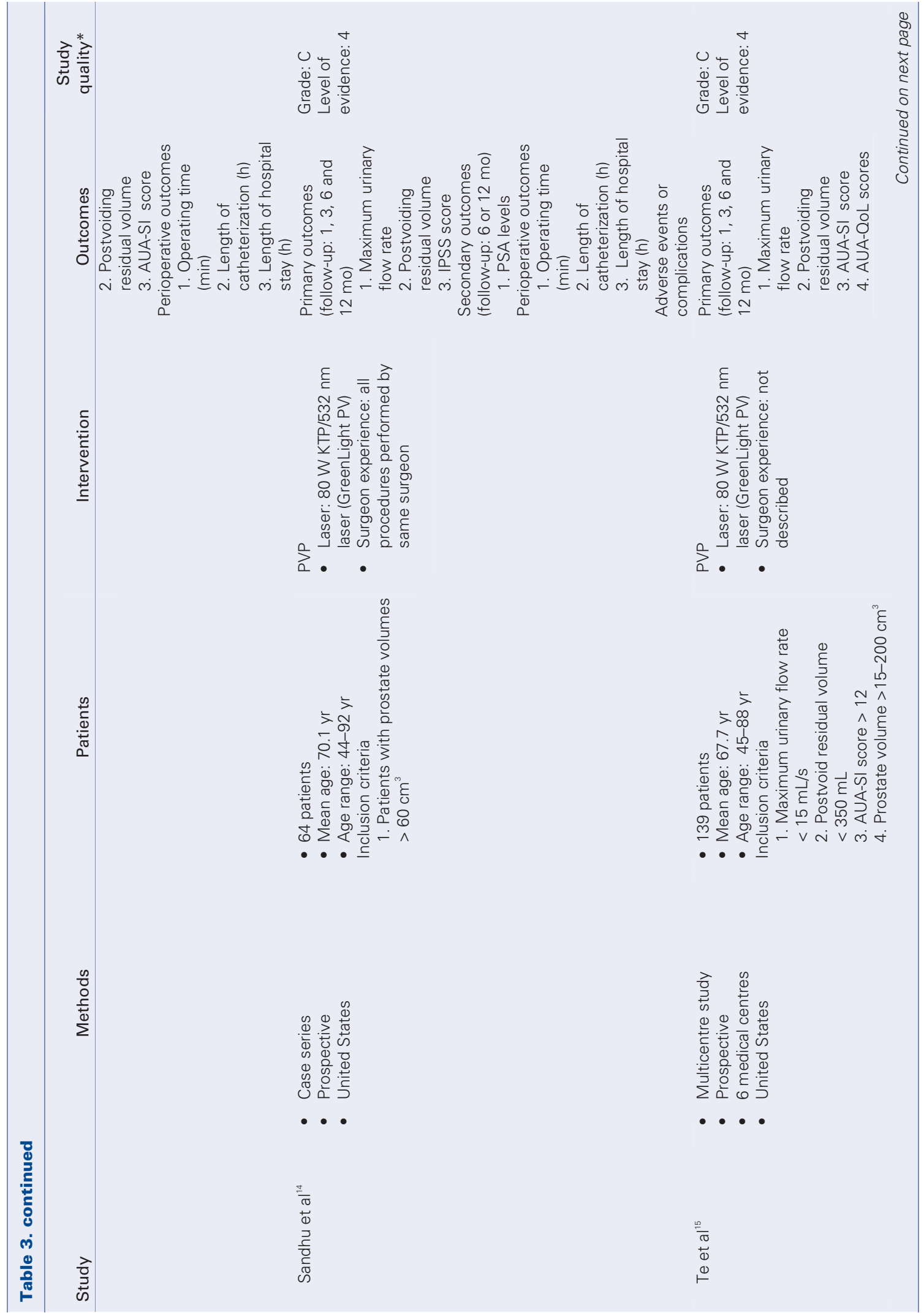




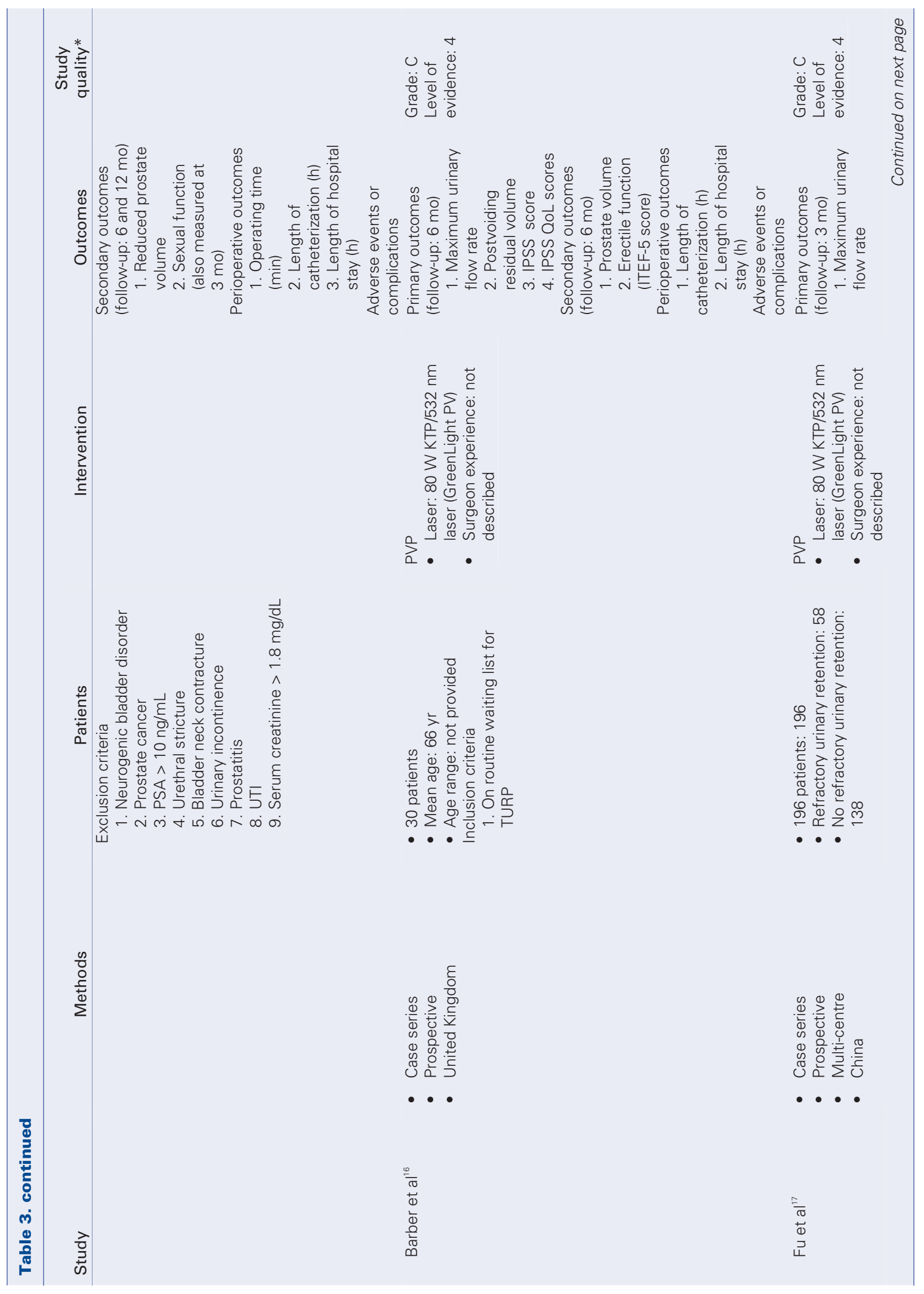




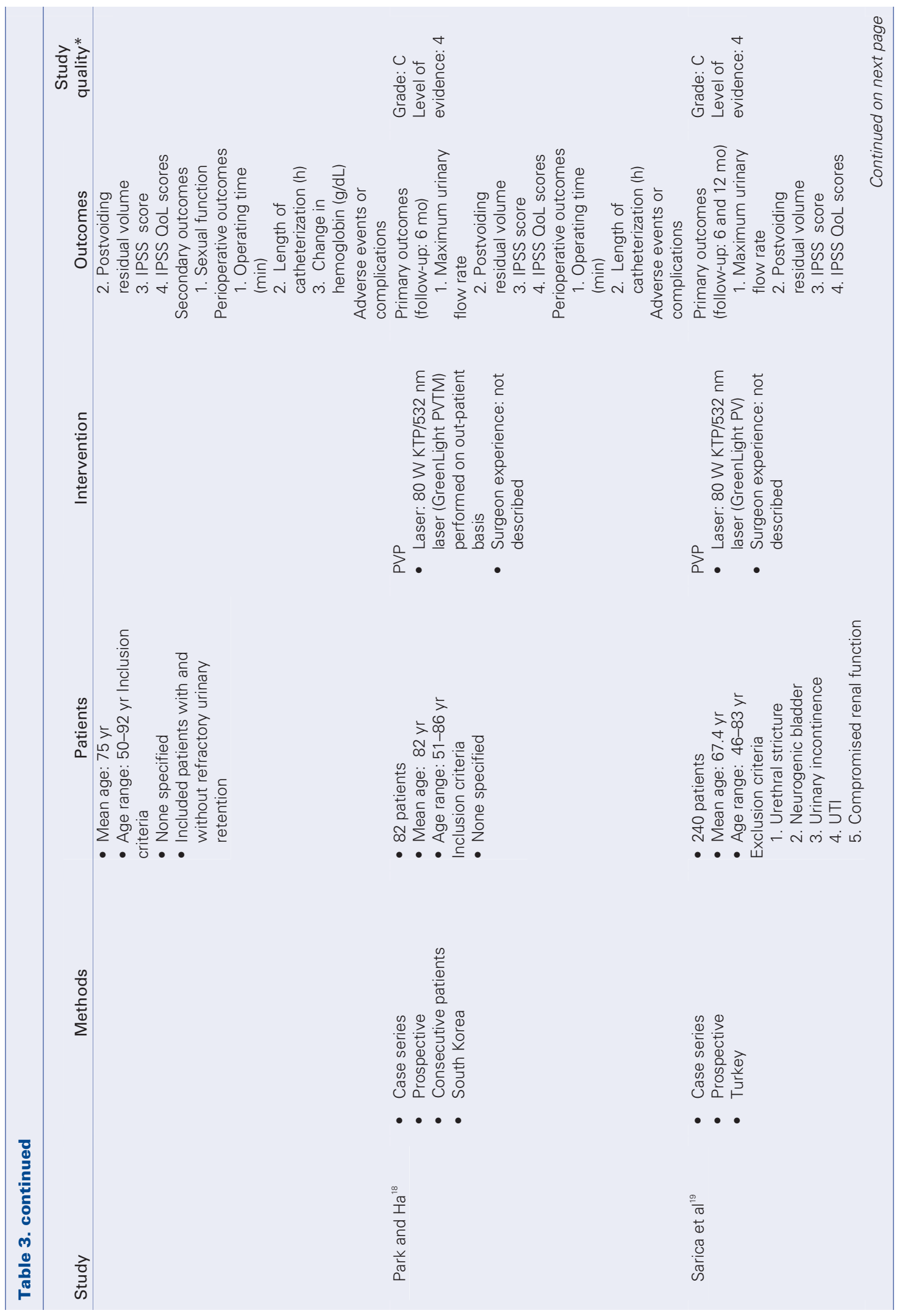




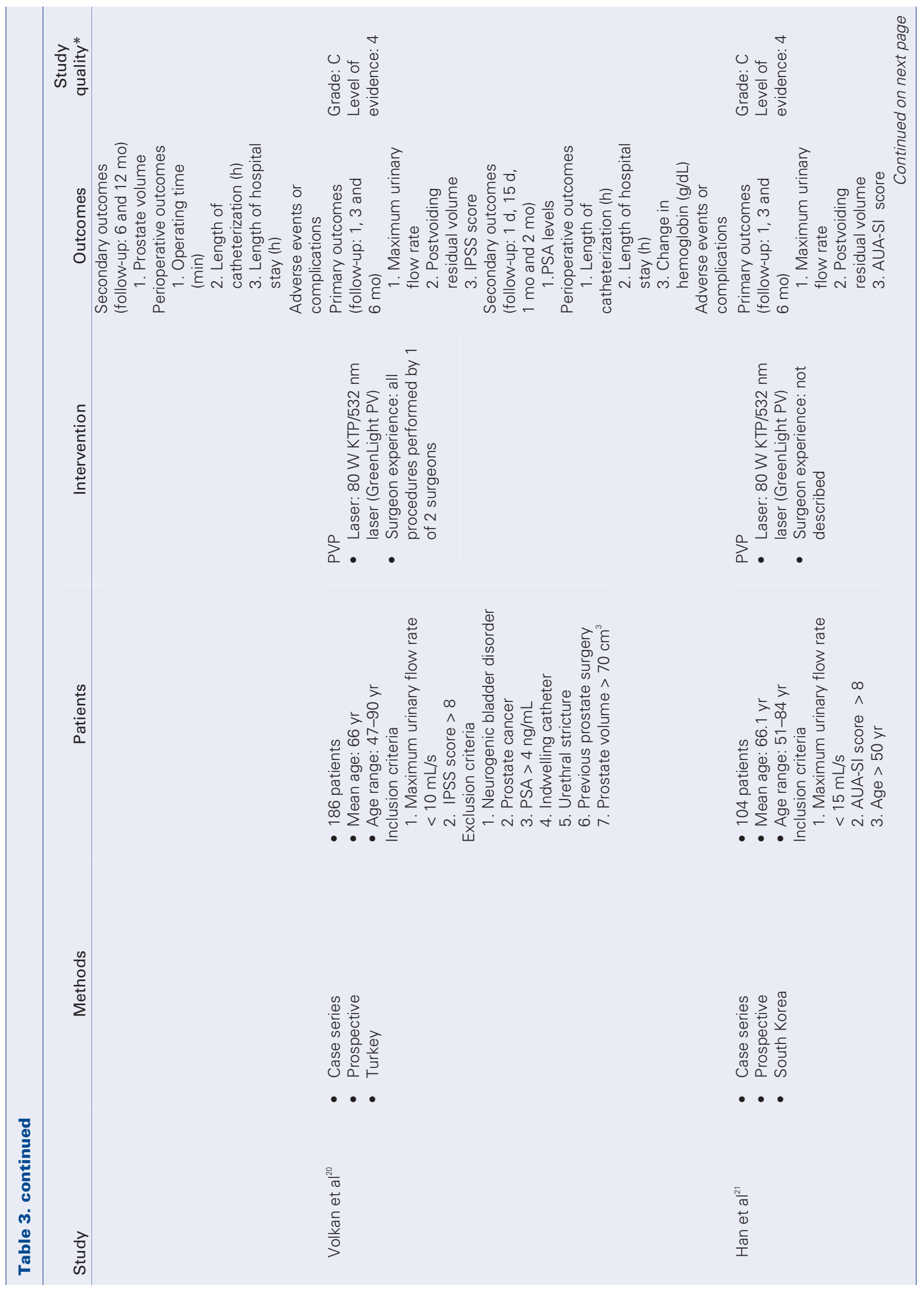




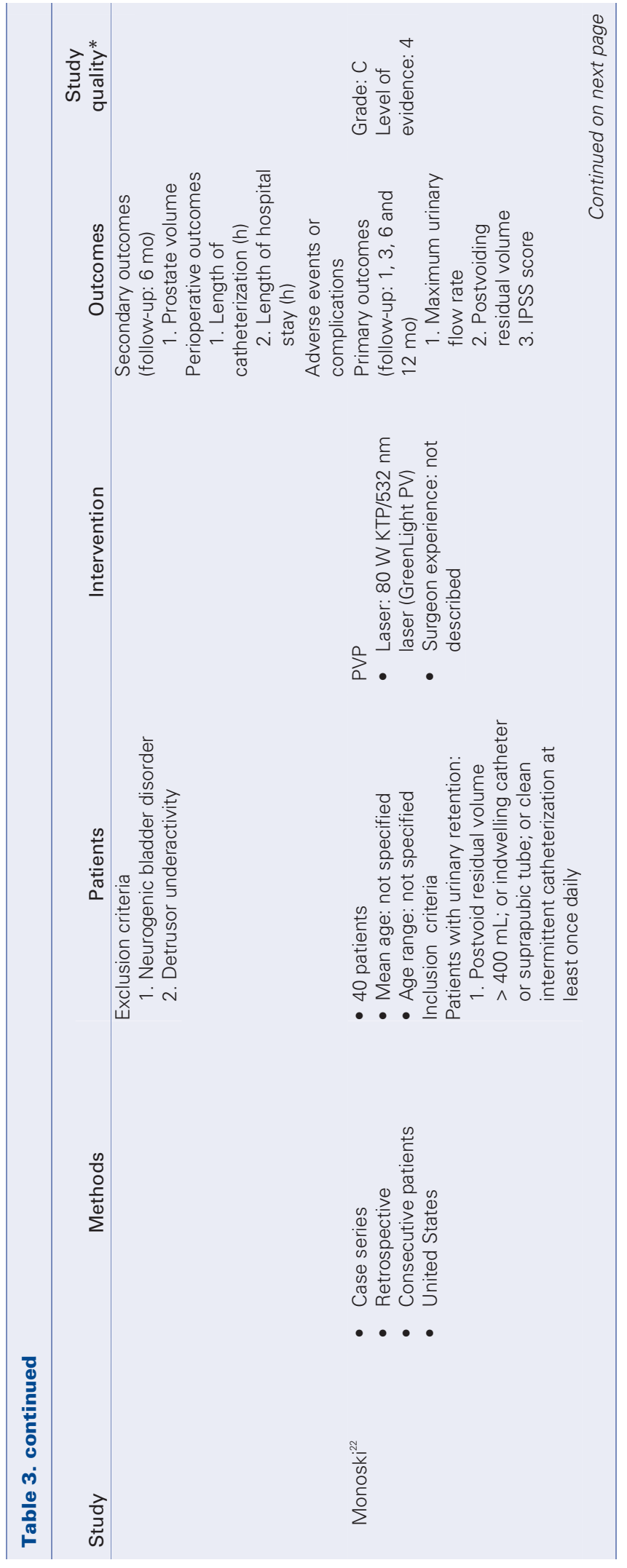

symptom score measured pre- and posttreatment. However, the types of secondary and operative outcomes measured differed.

\section{Overall quality of included studies}

As with most new technologies, the number of studies of PVP (i.e., evidence) available for review was limited. Nonetheless, the combined quality of these studies, and in turn the strength of evidence presented, was considered fair. Specifically, both comparative studies received high grades $\left(\mathrm{A}^{10}\right.$ and $\left.\mathrm{B}^{11}\right)$, while the 12 noncomparative studies ${ }^{12-23}$ were assigned a lower grade (C).

\section{Safety}

The following adverse events and complications were assessed: acute renal failure, urinary retention, clot retention, hematuria, dysuria, urinary tract infection, incontinence, urethral stricture, bladder neck contracture, bladder stenosis and sexual dysfunction (Table 4). Pooled complication rates from the 12 case series ranged from $0 \%$ for bladder stenosis to $9.3 \%$ for mild-to-moderate dysuria. When compared with those commonly reported for TURP, ${ }^{24}$ rates were either similar or considerably lower (i.e., urinary retention and clot retention). Further, none of the patients across the series required blood transfusions. Conversely, published transfusion rates for TURP range from $5 \%$ to $11 \% .^{24}$ Similar trends were observed from pooled analyses of relative risks for the 2 comparative studies (Table 5). With 1 exception (clot retention), none of the estimates were statistically significant, suggesting that in general the risk of experiencing a complication was comparable between treatment groups. Patients receiving PVP were significantly less likely to develop clot retention. Importantly, the absolute values of estimates were interpreted conservatively, as both studies involved relatively small numbers of patients. Nonetheless, accounting for the findings from all 14 studies, PVP appears to be a safe procedure, carrying with it a risk of adverse events and complications that appears to be similar to the "gold standard" treatment.

One study specifically examined the effect of physician experience on the risk of complications and adverse events to assess the learning curve associated with PVP. ${ }^{11}$ Prior to study inception, physicians experienced in performing TURP had 


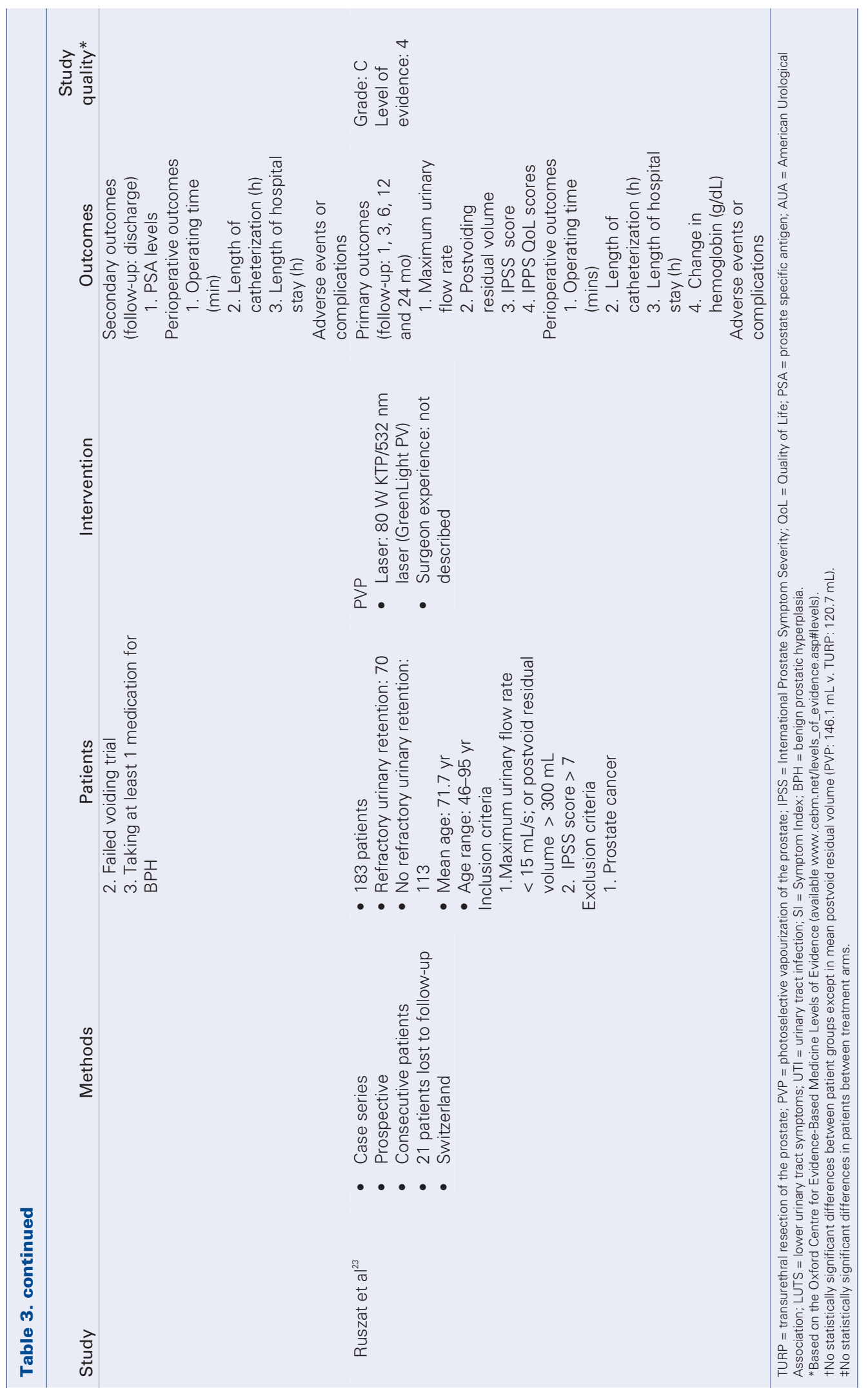




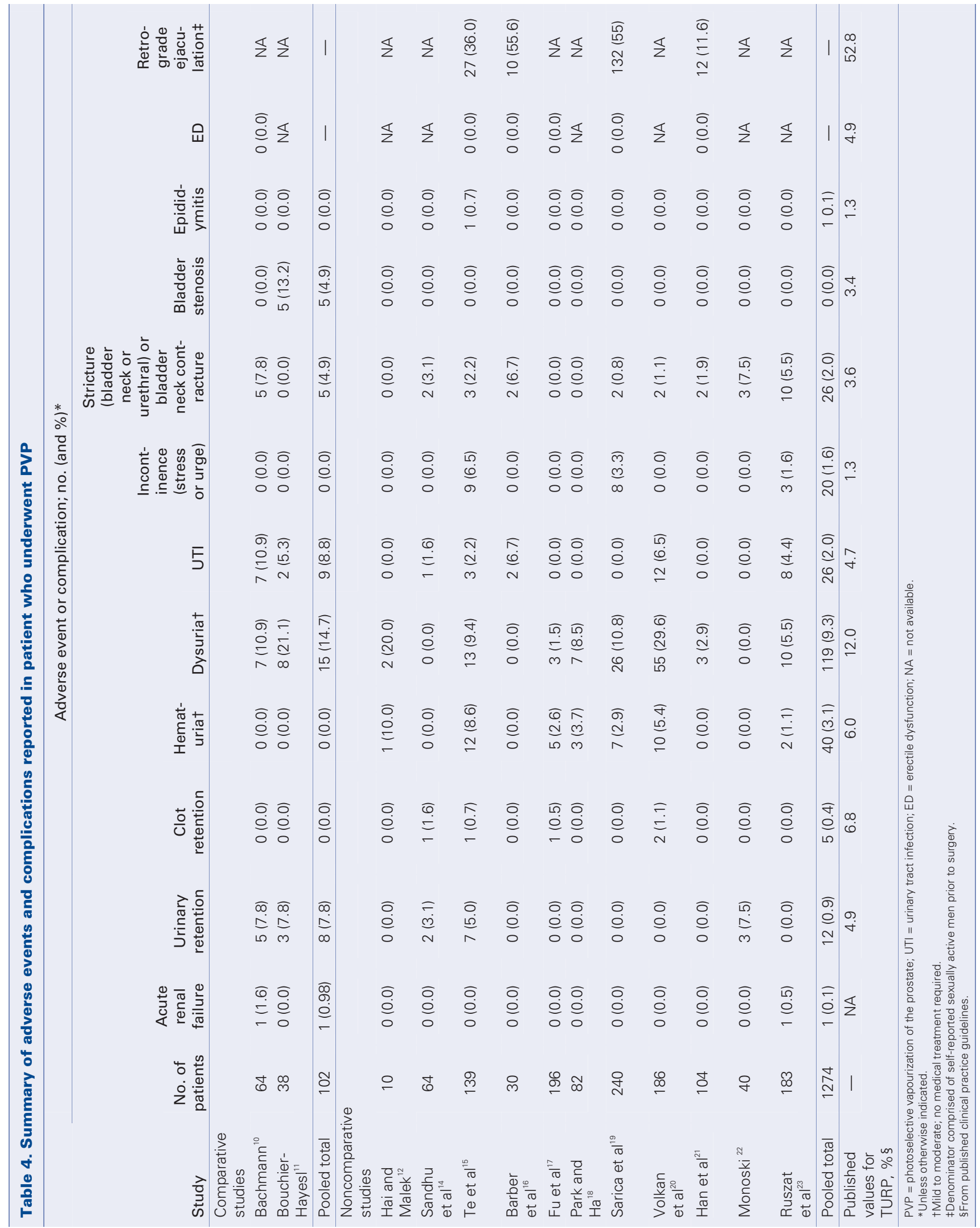


each completed less than 5 laser prostatectomies. The results demonstrated no difference in complication rates as the number of procedures increased.

\section{Efficacy}

\section{Operative outcomes}

Among the 12 case series, the average operating time ranged from 20 minutes to 137 minutes, increasing with preoperative prostate volume (Table 6). Average catheterization times varied from 7.6 hours to 43 hours; in 5 of the studies, a significant proportion of patients required no postoperative catheterization. In all but 1 of the studies, average hospital stays were less than 24 hours, with some patients going home as little as 5 hours after the procedure. Across studies that followed patients for 12 months, reoperation rates ranged from $0 \%$ to $7.5 \%$. When values were compared with those published for TURP, PVP appeared favourable in terms of catheterization time and length of patient hospitalization. ${ }^{24,25}$ Reoperation rates were similar for both procedures. These findings

Table 5. Adverse events and complications following PVP, compared with TURP

\begin{tabular}{|c|c|c|c|c|c|}
\hline \multirow[b]{2}{*}{$\begin{array}{l}\text { Adverse event or } \\
\text { complication }\end{array}$} & \multirow[b]{2}{*}{ Study } & \multicolumn{2}{|c|}{$\begin{array}{l}\text { Group; no. of } \\
\text { study patients } \\
\text { with adverse } \\
\quad \text { events }\end{array}$} & \multirow[b]{2}{*}{$\begin{array}{l}\text { Pooled estimate RR } \\
\qquad(95 \% \mathrm{Cl})\end{array}$} & \multirow{2}{*}{$\begin{array}{l}\text { Favours } \\
\text { PVP or } \\
\text { TURP }\end{array}$} \\
\hline & & PVP & TURP & & \\
\hline \multirow[t]{2}{*}{ Severe bleeding ${ }^{*}$} & Bachmann ${ }^{10} \dagger$ & $0 / 64$ & $4 / 37$ & 0.11 (0.01-1.99); NS & Neither \\
\hline & Bouchier-Hayes ${ }^{11} \ddagger$ & $0 / 38$ & $4 / 38$ & & \\
\hline \multirow[t]{2}{*}{ Acute renal failure } & Bachmann $^{10}$ & $0 / 64$ & $0 / 37$ & $3.00(0.01-1.99) ;$ NS & Neither \\
\hline & Bouchier-Hayes ${ }^{11}$ & $1 / 38$ & $0 / 38$ & & \\
\hline \multirow[t]{2}{*}{ Capsule perforation } & Bachmann $^{10}$ & $0 / 64$ & $0 / 37$ & 0.33 (0.01-7.93); NS & Neither \\
\hline & Bouchier-Hayes ${ }^{11}$ & $0 / 38$ & $1 / 38$ & & \\
\hline \multirow[t]{2}{*}{ Urinary retention } & Bachmann $^{10}$ & $5 / 64$ & $1 / 37$ & $2.94(0.64-13.56) ;$ NS & Neither \\
\hline & Bouchier-Hayes ${ }^{11}$ & $3 / 38$ & $1 / 38$ & & \\
\hline \multirow[t]{4}{*}{ Clot retention } & Bachmann $^{10}$ & $0 / 64$ & $1 / 37$ & $0.09(0.01-0.72)$ & PVP \\
\hline & Bouchier-Hayes ${ }^{11}$ & $0 / 38$ & $10 / 38$ & & \\
\hline & Bachmann $^{10}$ & $7 / 64$ & $4 / 37$ & $1.10(0.53-2.26) ; \mathrm{NS}$ & Neither \\
\hline & Bouchier-Hayes ${ }^{11}$ & $2 / 38$ & $3 / 38$ & & \\
\hline \multirow[t]{2}{*}{ Dysuria } & Bachmann $^{10}$ & $7 / 64$ & $4 / 37$ & 0.89 (0.34-2.33); NS & Neither \\
\hline & Bouchier-Hayes $^{11}$ & $2 / 38$ & $3 / 38$ & & \\
\hline \multirow[t]{2}{*}{ Urethral stricture } & Bachmann $^{10}$ & $5 / 64$ & $1 / 37$ & $0.59(0.02-18.42) ;$ NS & Neither \\
\hline & Bouchier-Hayes $^{11}$ & $0 / 38$ & $5 / 38$ & & \\
\hline \multirow[t]{2}{*}{ Bladder stenosis } & Bachmann $^{10}$ & $0 / 64$ & $0 / 37$ & 1.67 (0.43-6.49); NS & Neither \\
\hline & Bouchier-Hayes $^{11}$ & $5 / 38$ & $3 / 38$ & & \\
\hline \multirow[t]{2}{*}{ TUR syndrome } & Bachmann $^{10}$ & $0 / 64$ & $0 / 37$ & $0.33(0.01-7.93)$; NS & Neither \\
\hline & Bouchier-Hayes ${ }^{11}$ & $0 / 38$ & $1 / 38$ & & \\
\hline \multirow[t]{2}{*}{ ED } & Bachmann $^{10}$ & $0 / 64$ & $0 / 37$ & $0.19(0.01-4.66) ;$ NS & Neither \\
\hline & Bouchier-Hayes $^{11}$ & NA & NA & & \\
\hline \multirow[t]{2}{*}{ Recatheterization§ } & Bachmann $^{10}$ & $0 / 64$ & $0 / 37$ & $0.17(0.02-1.32) ; \mathrm{NS}$ & Neither \\
\hline & Bouchier-Hayes $^{11}$ & $1 / 38$ & $6 / 38$ & & \\
\hline \multirow[t]{2}{*}{ Transfusion } & Bachmann $^{10}$ & $0 / 64$ & $0 / 37$ & 0.33 (0.01-7.93); NS & Neither \\
\hline & Bouchier-Hayes $^{11}$ & $0 / 38$ & $1 / 38$ & & \\
\hline \multicolumn{6}{|c|}{ 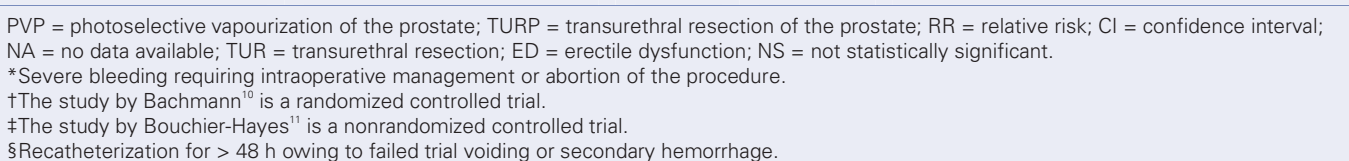 } \\
\hline
\end{tabular}




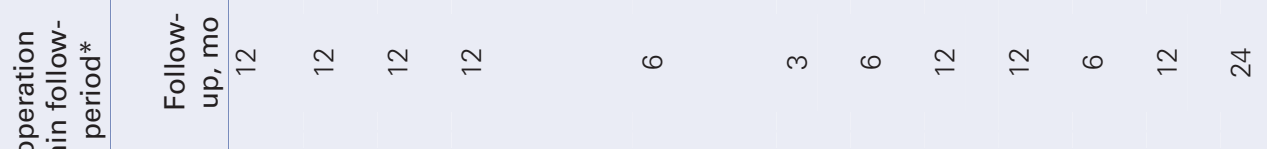

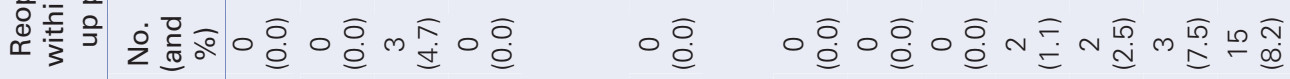

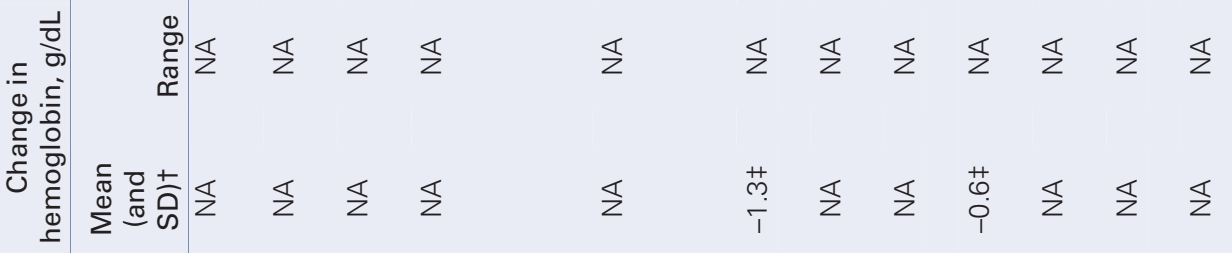

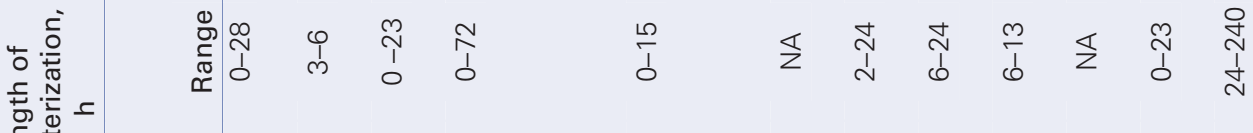

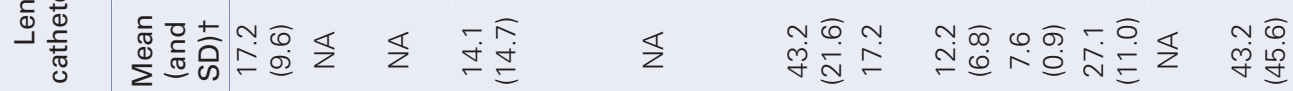

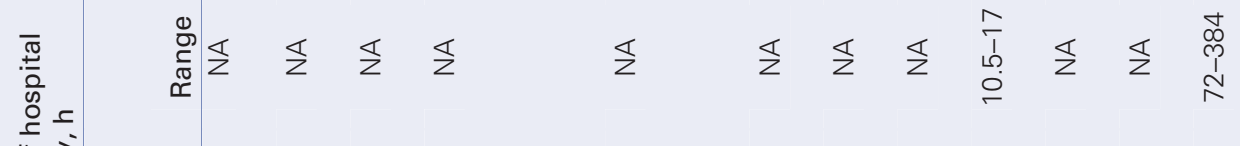

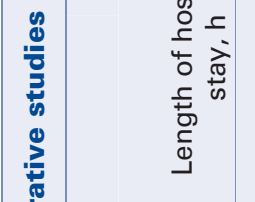

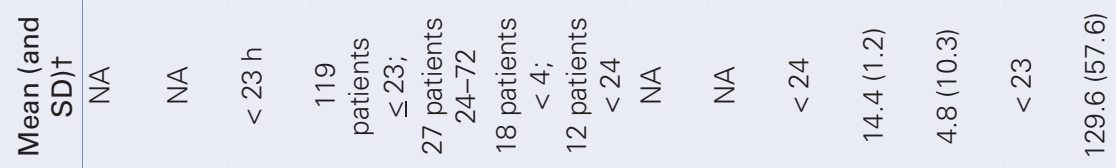

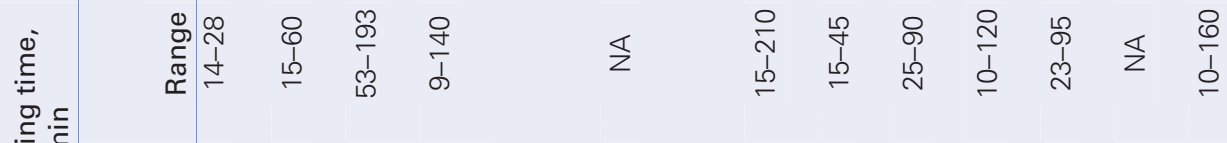

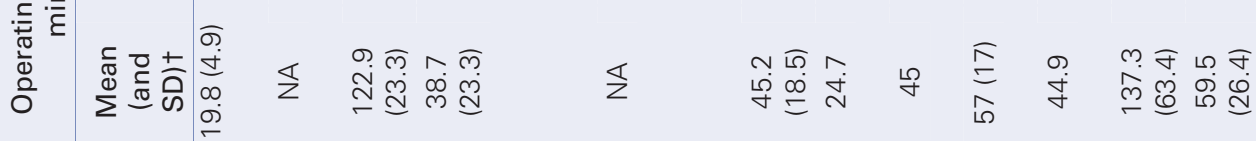

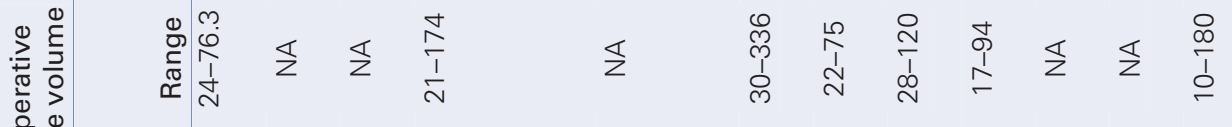

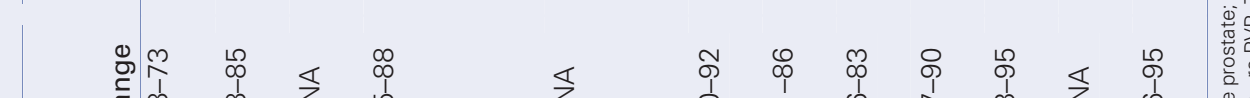

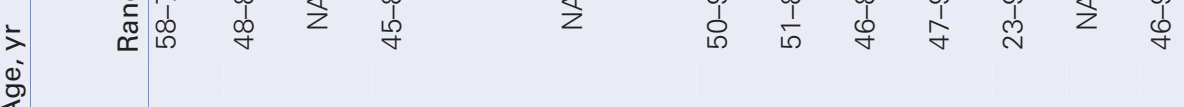

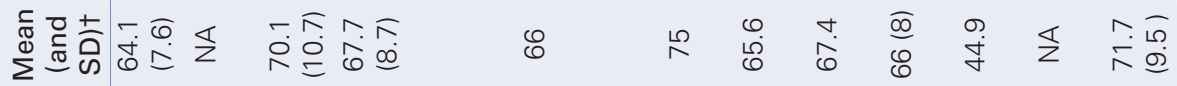

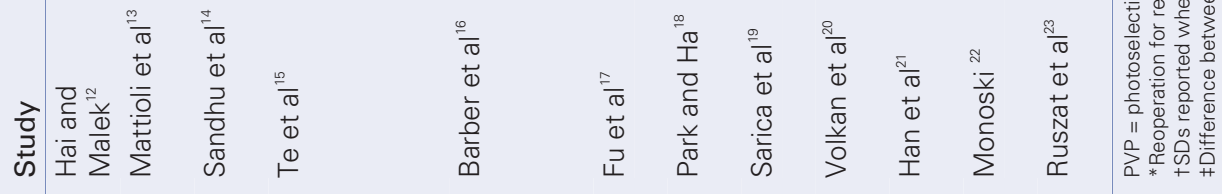


paralleled those from analyses of the 2 comparative studies (Table 7). No statistically significant differences in operating times and reoperation rates were observed between treatment groups. However, catheterization times and hospital stays were statistically significantly shorter for the PVP group.

\section{Primary outcomes}

Despite variations in length of follow-up and timing of the first postoperative visit, all 12 case series reported comparable patterns of improvement in functional outcomes. Specifically, percent cumulative improvements in peak urinary flow rates, peak residual volumes and symptom scores from preoperative levels remained statistically significant throughout the follow-up period of each study (Table 8, Table 9, Table 10). Six of the series also measured changes in quality of life (bother) scores, and reported consistent statistically significant improvements over time (Table 11). Pooled values were compared with those published for TURP at each follow-up point and found to be similar (Table 8, Table 9, Table 10). A meta-analysis of results from the first follow-up visit (i.e., the only data available for both studies) in the comparative studies revealed the same trends. There were no statistically significant differences in improvements in peak flow rates, post residual volumes, symptom scores or quality of life scores between treatment groups (Table 12).

Table 7. Operative outcomes following PVP, compared with TURP, from included comparative studies

\begin{tabular}{|c|c|c|c|c|c|}
\hline \multirow[b]{2}{*}{ Parameter } & & \multicolumn{2}{|c|}{ Group; mean (and SD) } & \multirow{2}{*}{$\begin{array}{c}\text { Pooled effect } \\
\text { estimate weighted } \\
\text { mean difference } \\
(95 \% \mathrm{Cl}) \dagger\end{array}$} & \multirow[b]{2}{*}{$\begin{array}{l}\text { Favours } \\
\text { PVP or } \\
\text { TURP }\end{array}$} \\
\hline & & PVP & TURP & & \\
\hline \multirow[t]{3}{*}{ Age, yr } & & & & NA & NA \\
\hline & Bachmann ${ }^{10} \mp$ & $71.0(9.3)$ & $68.7(7.9)$ & $p>0.05$ & \\
\hline & Bouchier-Hayes ${ }^{11} \S$ & $\begin{array}{c}65.23 \\
\text { (range 51-81) }\end{array}$ & $\begin{array}{c}66.23 \\
\text { (range 55-80) }\end{array}$ & $p>0.05$ & \\
\hline \multirow[t]{3}{*}{ Preoperative prostate volume, $\mathrm{cm}^{3}$} & & & & NA & NA \\
\hline & Bachmann $^{10}$ & $65.1(36.9)$ & $48.9(21.2)$ & $p>0.05$ & \\
\hline & Bouchier-Hayes ${ }^{11}$ & $\begin{array}{c}42.44 \\
\text { (range 16.5-82.6) }\end{array}$ & $\begin{array}{c}33.22 \\
\text { (range 15.4-67.5) }\end{array}$ & $p>0.05$ & \\
\hline \multirow[t]{3}{*}{ Operating time, $\min$} & & & & - & Neither \\
\hline & Bachmann $^{10}$ & $59.6(24.4)$ & $49.4(16.0)$ & $p=0.05$ (NS) & \\
\hline & Bouchier-Hayes ${ }^{11}$ & 30.24 & 31.33 & $p>0.05$ (NS) & \\
\hline \multirow[t]{3}{*}{ Length of hospital stay, $d$} & & & & & PVP \\
\hline & Bachmann $^{10}$ & $5.5(2.7)$ & $7.1(1.8)$ & -2.08 & \\
\hline & Bouchier-Hayes ${ }^{11}$ & $1.08(0.28)$ & $3.39(1.17)$ & $(-0.73$ to -1.42$)$ & \\
\hline \multirow[t]{3}{*}{ Length of catheterization, $\mathrm{h}$} & & & & & PVP \\
\hline & Bachmann $^{10}$ & $43.2(43.2)$ & $72(36)$ & -31.29 & \\
\hline & Bouchier-Hayes ${ }^{11}$ & $12.2(8.6)$ & $44.5(30.2)$ & $(-39.72$ to -22.87$)$ & \\
\hline \multicolumn{2}{|c|}{ Blood loss (change in hemoglobin), g/dL } & & & - & PVP \\
\hline & Bachmann ${ }^{10}$ & 0.7 & 1.7 & $p=0.027$ & \\
\hline & Bouchier-Hayes ${ }^{11}$ & 0.5 & 1.5 & $p<0.001$ & \\
\hline \multirow[t]{3}{*}{ Reoperation within follow-up period } & & No. of patients & No. of patients & $\mathrm{RR}(95 \% \mathrm{Cl})$ & Neither \\
\hline & Bachmann ${ }^{10}$ & 0 & 0 & $4.87(0.24-98.18)$ & \\
\hline & Bouchier-Hayes ${ }^{11}$ & 2 & 0 & (NS) & \\
\hline \multicolumn{6}{|c|}{$\begin{array}{l}\text { PVP = photoselective vapourization of the prostate; TURP = transurethral resec } \\
\text { NS = not statistically significant; RR = relative risk. } \\
\text { *Unless otherwise indicated. } \\
\text { tWeighted mean differences were calculated where reported data permitted. } \\
\text { fThe study by Bachmann }{ }^{10} \text { is a randomized controlled trial. } \\
\text { §The study by Bouchier-Hayes" is a nonrandomized controlled trial. }\end{array}$} \\
\hline
\end{tabular}


Table 8. Change in peak urinary flow after PVP during follow-up across studies

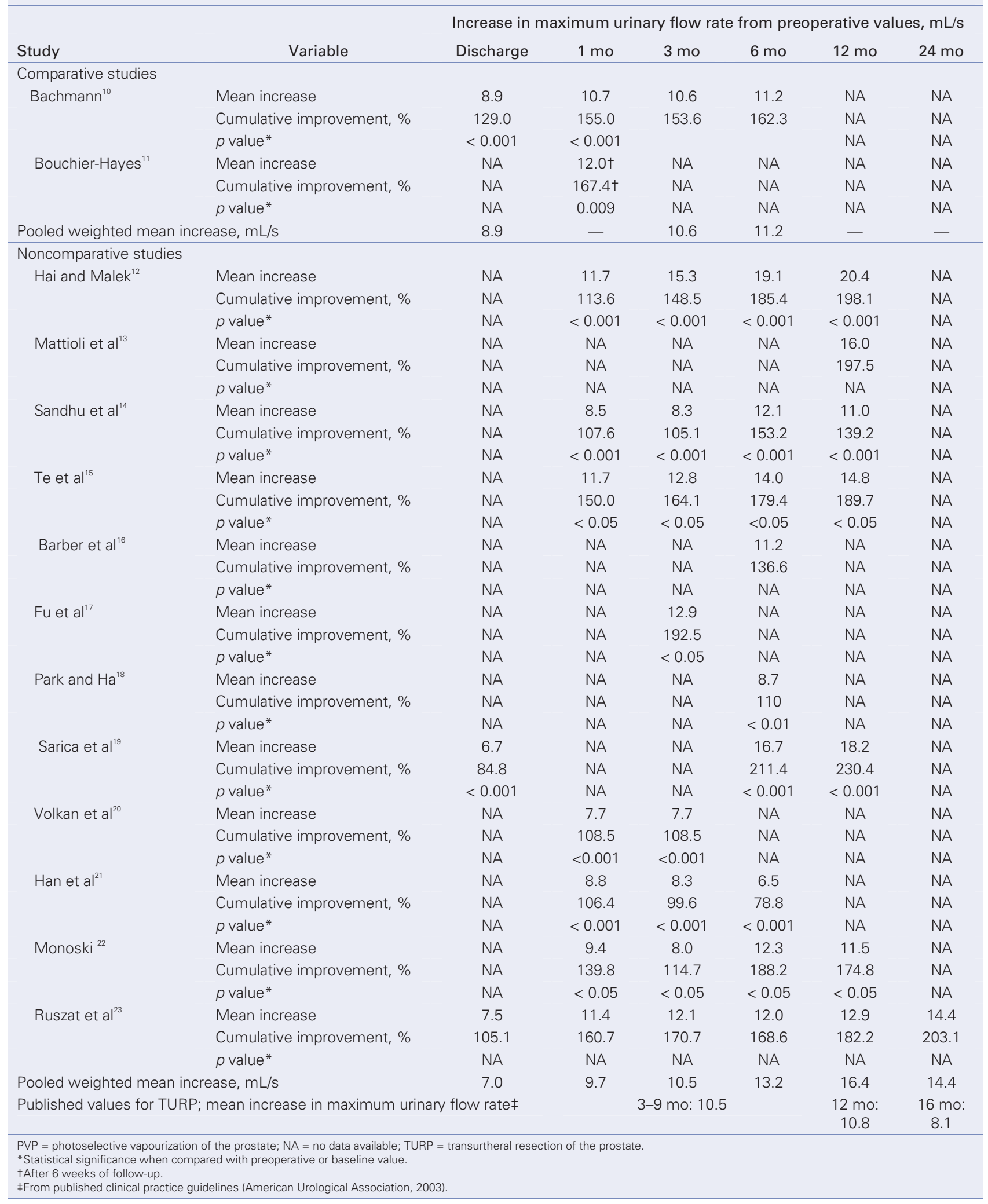




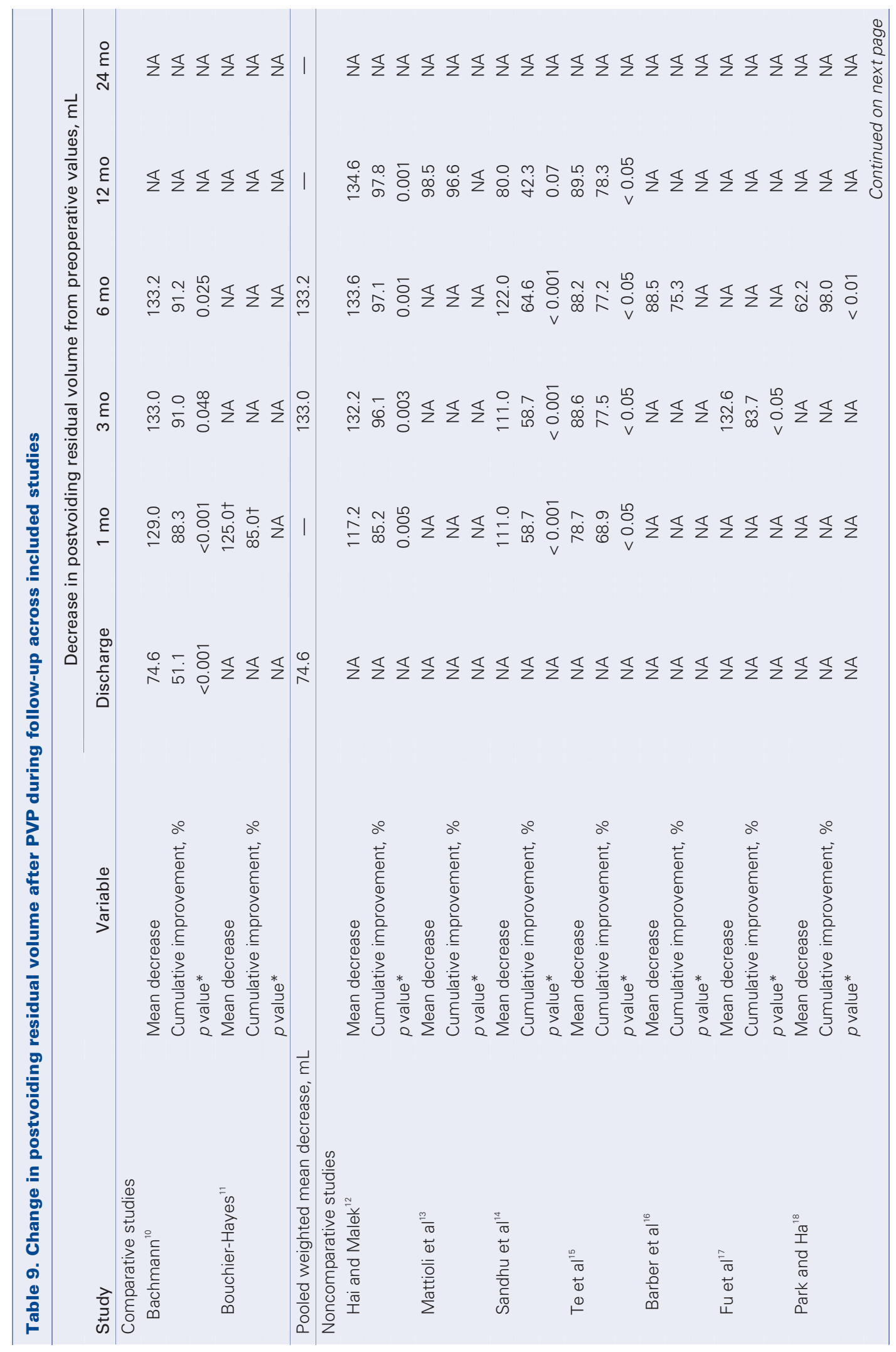




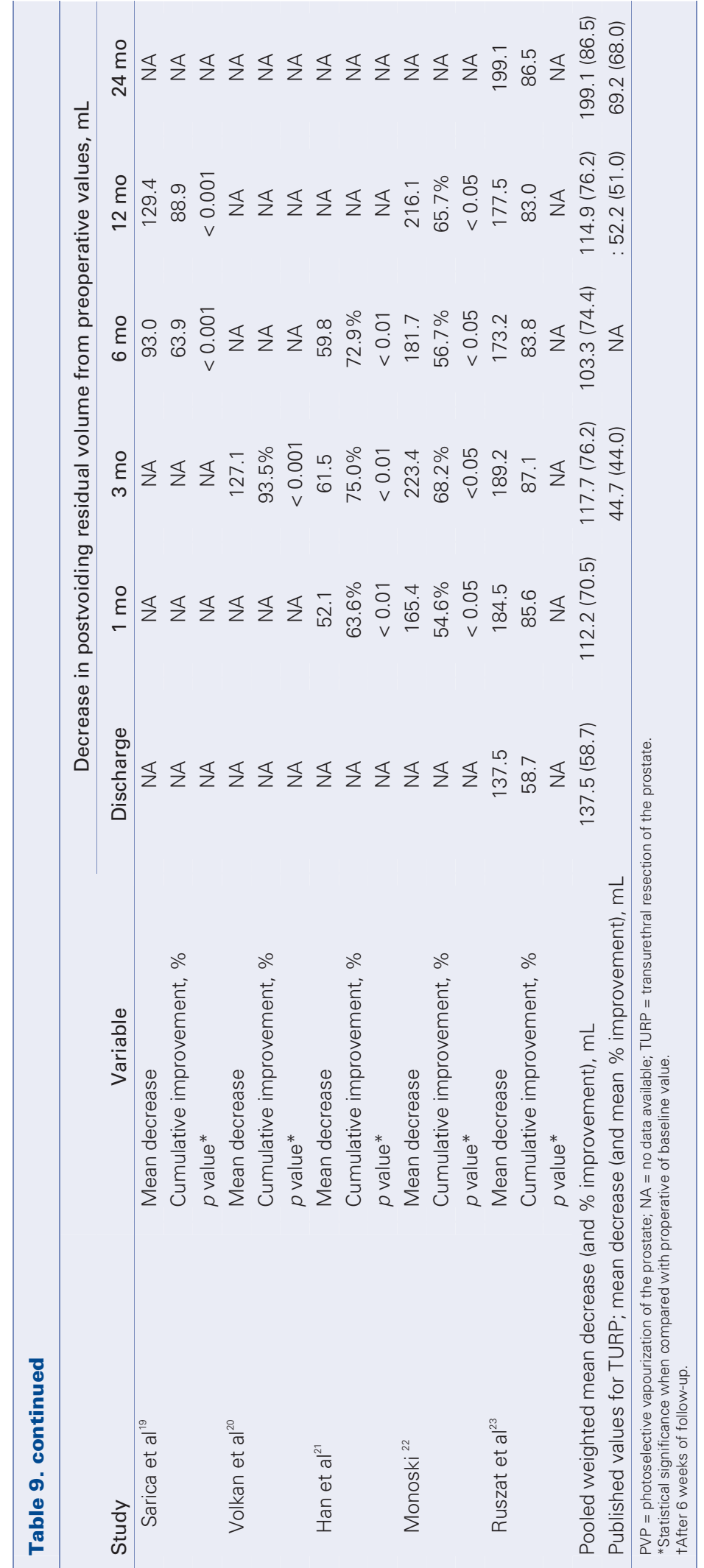

\section{Secondary outcomes}

Of the 12 case series, 3 examined the effect of PVP on sexual functioning through a comparison of pre- and postprocedural rates of erectile dysfunction. ${ }^{15-17}$ No differences were found across studies. Only 1 of the comparative studies evaluated sexual function, with patients completing a selfadministered questionnaire both before surgery and during each follow-up visit. No differences from baseline (i.e., presurgery) or between the TURP and PVP groups were noted. Prostate specific antigen levels, measured in 4 of the case series and 1 of the comparative studies, decreased by about $30 \%-40 \%$, an amount similar to that reported for TURP. 10,12,14,20,22 Across all 5 case series and both comparative studies that assessed changes in prostate volume, reductions of $30 \%-42 \%$ were found. According to the results of the 2 comparative studies, these values were roughly equivalent to those for TURP. ${ }^{10,11}$

\section{Performance of PVP in high-risk groups}

Two of the case series included patients on anticoagulants, among whom the prevalence of cardiovascular disease, cerebrovascular disease and peripheral vascular disease was high $(31 \%)$ and the use of TURP was contraindicated. ${ }^{14,26}$ In all patients, PVP was performed successfully with no reports of thromboembolic or bleeding events. No transfusions were required. Functional outcomes were similar to those reported for the non-high risk patients, suggesting that PVP may be both a safe and efficacious option for high-risk patients.

\section{Durability of PVP}

While the short-term efficacy of PVP appears similar to that of TURP, the lack of data beyond 2 years precludes assessment of its durability (i.e., longterm efficacy).

\section{Economic considerations}

\section{Summary of existing economic analyses}

We found 4 economic analyses of PVP: 2 peerreviewed studies, ${ }^{11,27} 1$ conference abstract ${ }^{28}$ and 1 government report. ${ }^{29} \mathrm{~A}$ brief description of each analysis is presented in Table 13. Although the 


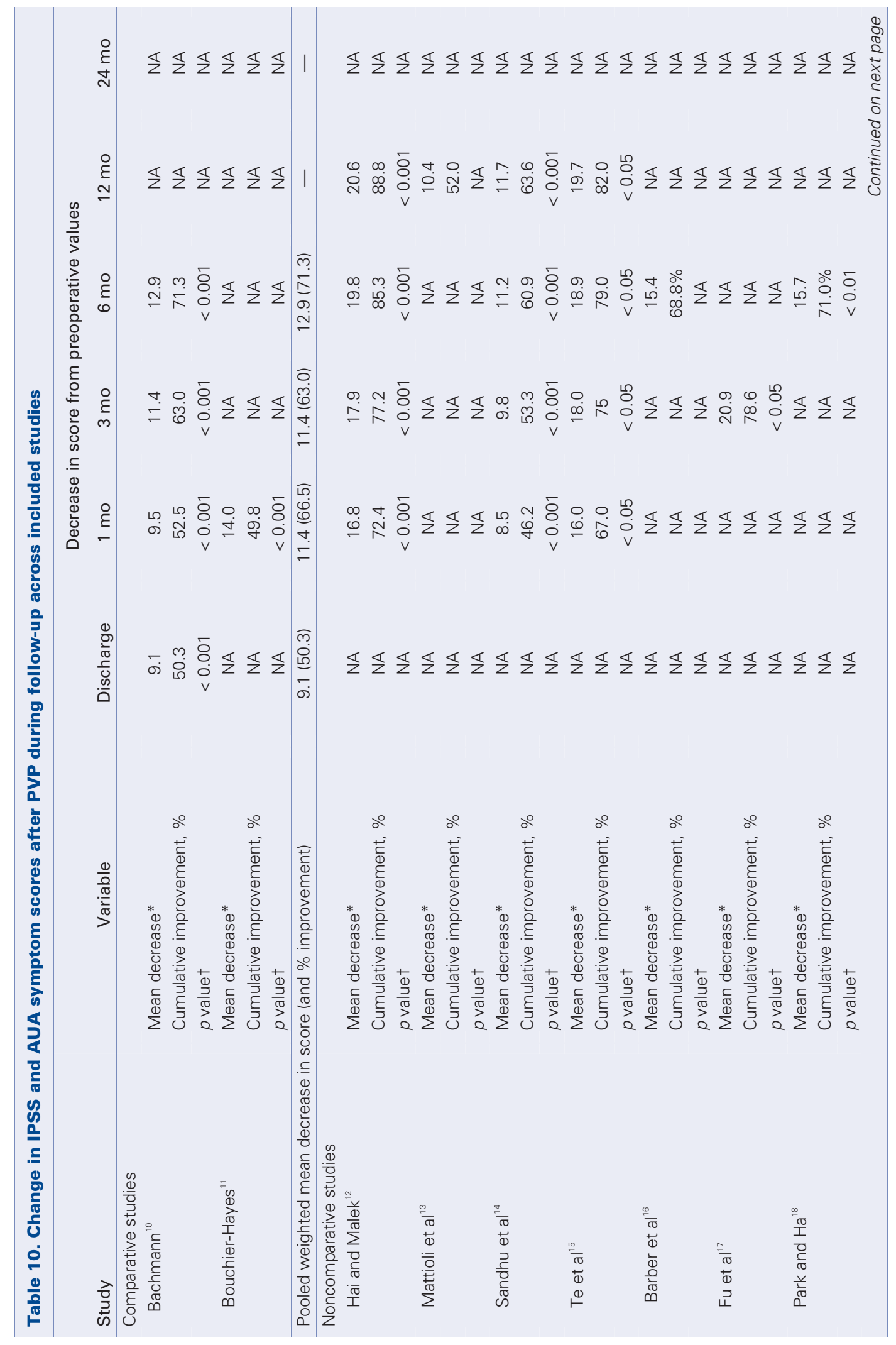




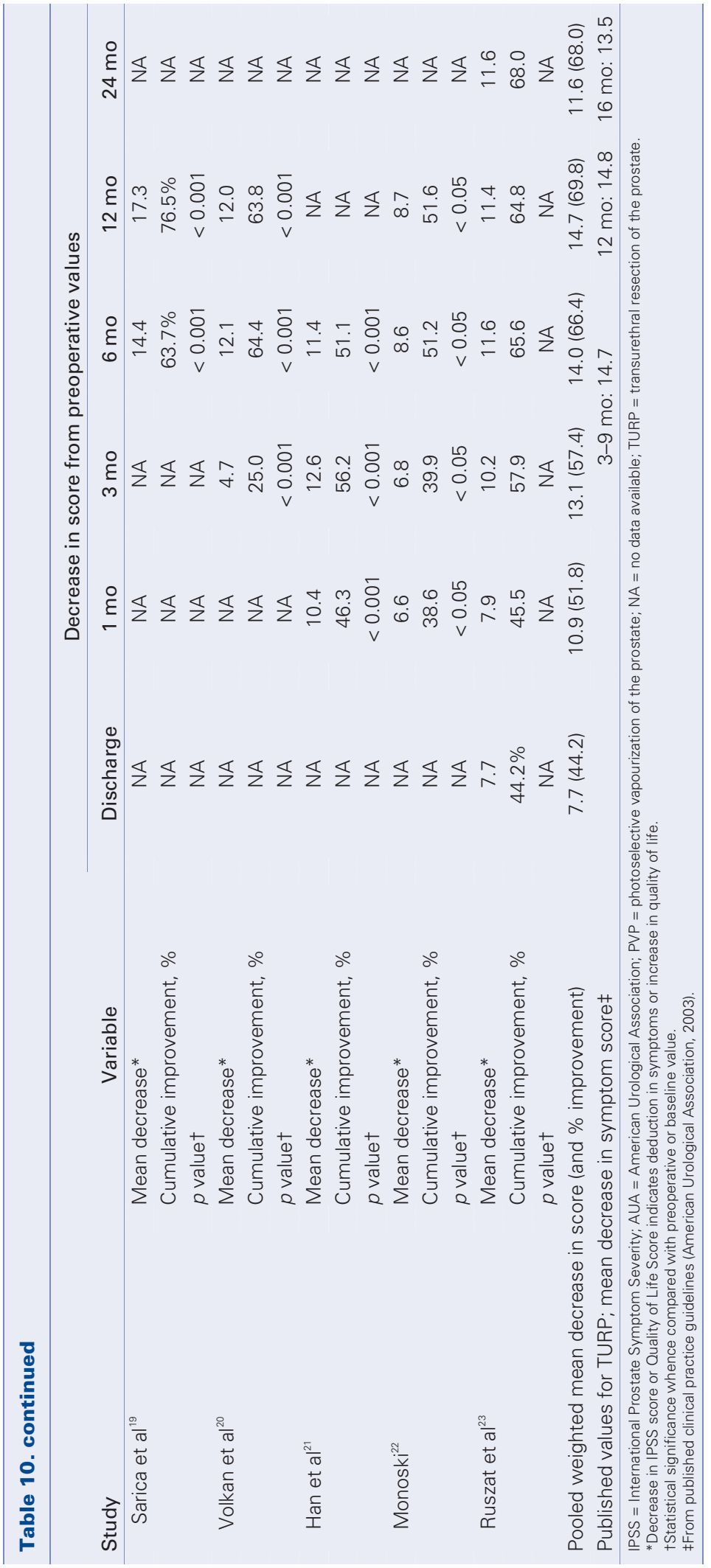

quality of the studies reviewed varied, the findings did not. All 4 demonstrated that on a per case or per patient basis, the cost of PVP was less than that of TURP.

\section{An economic model comparing TURP with PVP in Alberta}

Based on findings from the review of clinical evidence for PVP compared with TURP, which demonstrated similar safety and efficacy profiles for the 2 treatments, a cost-minimization analysis from the payer's perspective (i.e., Alberta's Ministry of Health and Wellness) was performed. Information on direct costs for TURP was obtained from the Ministry. Since PVP is not yet offered in Alberta, costs for the procedure were collected from the manufacturer (D. Okamoto, American Medical Systems Inc., Minnetonka, Minnesota: personal communication, 2007) and the Ministry of Health and Long-Term Care in Ontario, ${ }^{29}$ where PVP is already being performed. This information, which was in turn used to compare PVP with TURP against a comprehensive list of cost elements, is summarized in Table 14. The following assumptions were made:

1. The preoperative physical examination by a physician and the diagnostic tests used to establish $\mathrm{BPH}$ are the same regardless of treatment choice; thus, the preoperative costs for both groups are the same.

2. Physician and nursing costs for both groups are the same.

3. PVP requires the use of disposable laser fibres, which are estimated in the Ontario government report to cost Can $\$ 650$ each. ${ }^{29}$ For TURP, a resecting loop is required; these have been estimated to cost Can $\$ 100$ each. Regarding capital costs, TURP will already be available at the hospital or institution so there will be no additional capital expenditures. As a new program, PVP will require the purchase of a PVP GreenLight laser system (specifically, the new higher powered GreenLight HPS), which is estimated to cost Can $\$ 125$ 000. This system is built to function in standard operating room suites without the need for external water connections or specialized electrical utilities. Therefore, it is assumed that no installation costs will be incurred.

Maintenance costs after the first year (after the warranty has expired) are estimated to be Can\$10 000 per year (D. Okamoto, American Medical Systems Inc., Minnetonka, Minnesota: 


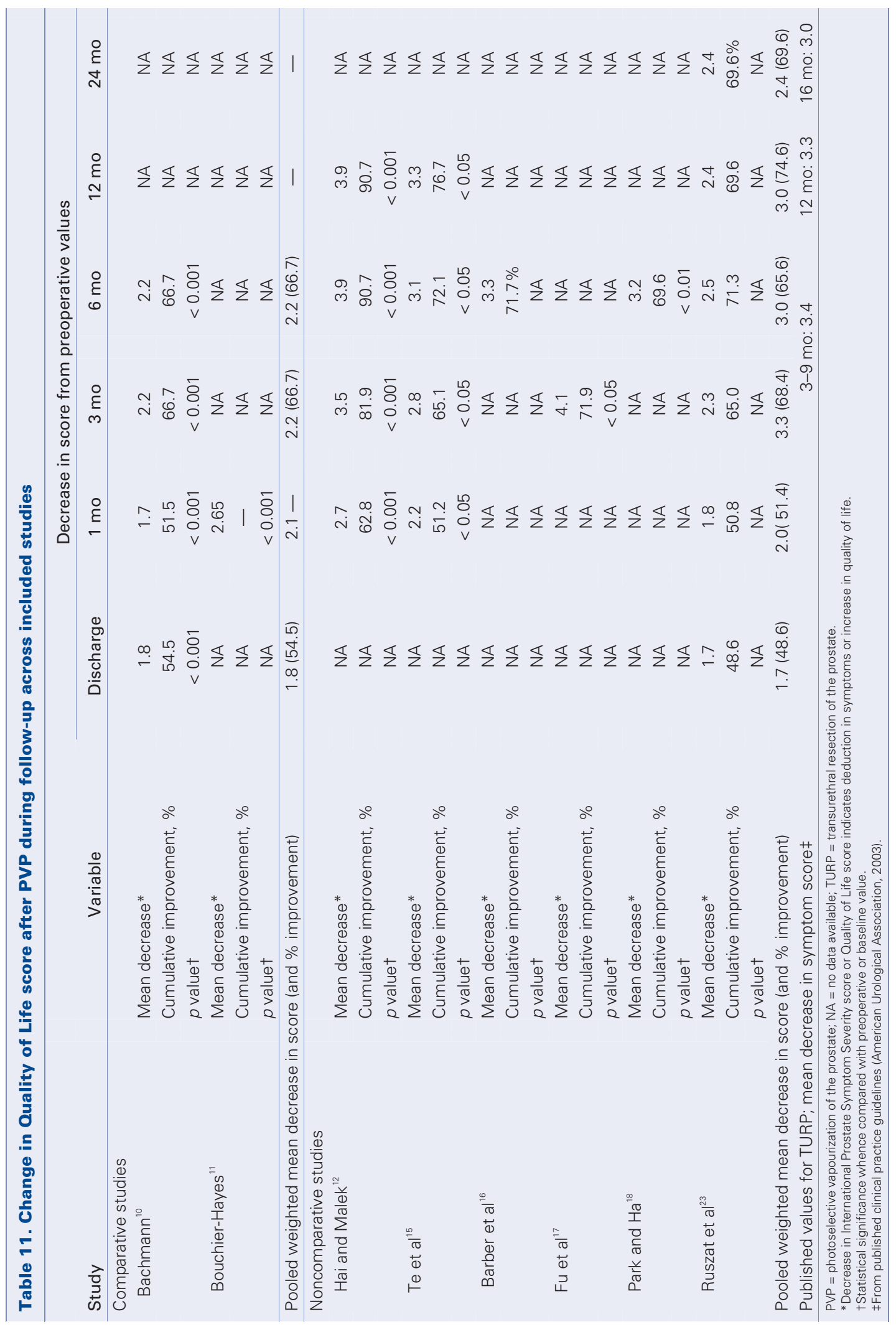


personal communication, 2007). The equipment is amortized over 5 years, with an average of 1400 procedures each year (based on trends in Alberta over the past 5 years). However, early in its diffusion, patient throughput will likely be considerably less and the annual amortized costs will be substantially greater.

4. PVP patients will require observation in a stepdown day ward after the procedure. This will contribute to the cost of the PVP treatment. For the TURP patients, an average length of hospital stay of 2 days is anticipated (using administrative data from Alberta Health and Wellness for the fiscal year 2004/05, median length of stay was 2 days). ${ }^{30}$

5 . There are no differences between the rates of complications and adverse events in the 2 groups. Also, since long-term data on PVP is limited, it is assumed (conservatively) that the retreatment rates will be the same in both groups.

Table 14 demonstrates that differences in per treatment costs between PVP and TURP will most likely be due to differences in the cost of consumables, capital equipment and length of hospital stays. As previously mentioned, the only Canadian data for PVP (from the Ontario Ministry of Health and Long-Term Care) found the cost per procedure was less than one-half that of TURP (Can\$3887 v. Can\$1184). Therefore, even if the costs of capital depreciation and system maintenance are added to these figures, the difference in cost will still be substantial. Since the actual cost per TURP in Alberta is about $\$ 3437.87$ (a value similar to that reported in Ontario), it would not be unreasonable to expect per case PVP costs in Alberta to lie between Can $\$ 1500$ and Can $\$ 1800$, making it the less costly alternative.

Table 12. Mean changes in functional outcomes after PVP, compared with TURP, at first postdischarge follow-up visit of included comparative studies

\begin{tabular}{|c|c|c|c|c|c|}
\hline \multirow[b]{2}{*}{ Functional outcome } & \multirow[b]{2}{*}{$\begin{array}{l}\text { Study } \\
\text { type }\end{array}$} & \multicolumn{2}{|c|}{$\begin{array}{l}\text { Intervention; } \\
\text { mean difference } \\
\text { between pre- and } \\
\text { postoperative } \\
\text { values }\end{array}$} & \multirow{2}{*}{$\begin{array}{l}p \text { value; } \\
\text { difference } \\
\text { between } \\
\text { group }\end{array}$} & \multirow[b]{2}{*}{$\begin{array}{c}\text { Favours } \\
\text { PVP or } \\
\text { TURP }\end{array}$} \\
\hline & & PVP & TURP & & \\
\hline \multicolumn{6}{|l|}{ Postvoiding flow } \\
\hline \multirow[t]{2}{*}{ Increase, $\mathrm{mL} / \mathrm{s}$} & Non-RCT & 10.7 & 12.6 & $>0.05 ; \mathrm{NS}$ & Neither \\
\hline & $\mathrm{RCT}$ & 12.0 & 8.6 & $>0.05 ; \mathrm{NS}$ & Neither \\
\hline \multirow[t]{2}{*}{ \% Improvement } & Non-RCT & 155.0 & 183.0 & $>0.05 ; \mathrm{NS}$ & Neither \\
\hline & $\mathrm{RCT}$ & 167.4 & 149.0 & $>0.05 ; \mathrm{NS}$ & Neither \\
\hline \multicolumn{6}{|c|}{ Postvoiding residual volume } \\
\hline \multirow[t]{2}{*}{ Decrease, $\mathrm{mL}$} & Non-RCT & 129.0 & 93.9 & $>0.05 ; \mathrm{NS}$ & Neither \\
\hline & $\mathrm{RCT}$ & 125.0 & 86.0 & $>0.05 ; \mathrm{NS}$ & Neither \\
\hline \multirow[t]{2}{*}{ \% Improvement } & Non-RCT & $88 . Z$ & 77.8 & $>0.05 ; \mathrm{NS}$ & Neither \\
\hline & $\mathrm{RCT}$ & NA & NA & - & - \\
\hline \multicolumn{6}{|l|}{ IPSS } \\
\hline \multirow[t]{2}{*}{ Decrease in score } & Non-RCT & 9.5 & 6.7 & $>0.05 ; \mathrm{NS}$ & Neither \\
\hline & $\mathrm{RCT}$ & 14.0 & 12.9 & $>0.05 ; \mathrm{NS}$ & Neither \\
\hline \multirow[t]{2}{*}{ \% Improvement } & Non-RCT & 52.5 & 38.7 & $>0.05 ; \mathrm{NS}$ & Neither \\
\hline & $\mathrm{RCT}$ & 49.8 & 50.2 & $>0.05 ; \mathrm{NS}$ & Neither \\
\hline \multicolumn{6}{|l|}{ Quality of Life score } \\
\hline \multirow[t]{2}{*}{ Decrease in score } & Non-RCT & 1.7 & 1.3 & $>0.05 ; \mathrm{NS}$ & Neither \\
\hline & $\mathrm{RCT}$ & 2.7 & 2.9 & $>0.05 ; \mathrm{NS}$ & Neither \\
\hline \multirow[t]{2}{*}{ \% Improvement } & Non-RCT & 51.5 & 38.2 & $>0.05 ; \mathrm{NS}$ & Neither \\
\hline & $\mathrm{RCT}$ & NA & NA & - & - \\
\hline
\end{tabular}




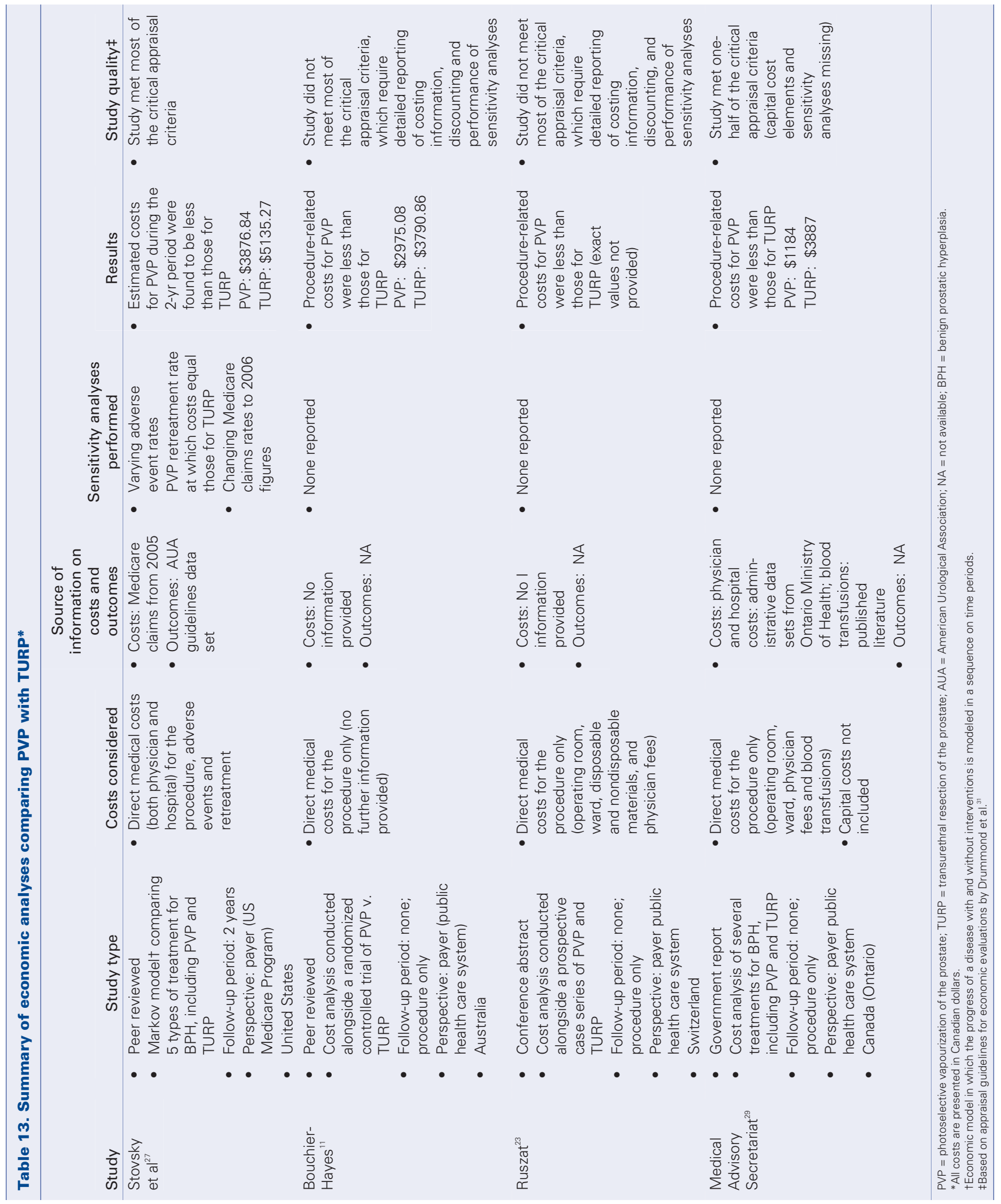




\section{Interpretation}

Although there are several commentaries and narrative reviews of PVP with earlier versions of the KTP laser, ${ }^{1-3}$ our paper presents the first meta-analysis and systematic review of the safety, efficacy and economic consequences of PVP using the first commercially available KTP laser system (i.e., $80 \mathrm{~W}$ Greenlight PV System). Despite limited clinical evidence, findings were consistent across all 12 case series and both comparative studies, suggesting that, with 2 exceptions (blood transfusion and clot retention, which both favoured PVP), adverse events and complication rates are likely similar for PVP and TURP. Therefore, it can be concluded that PVP offers an acceptable safety profile, even in anticoagulated patients for whom TURP is often contraindicated. ${ }^{26}$ Regarding efficacy, PVP was considered favourable to TURP in terms of length of patient hospitalization and catheterization time. There were no differences between the 2 procedures in operative or clinical outcomes. Importantly, none of the studies measured outcomes before 4-6 weeks following surgery; thus, it was not possible to assess the value to patients of shorter hospital stays and catheterization times. This may be significant, especially in patients who are still in the workforce. Nonetheless, based on the outcomes

\begin{tabular}{|c|c|c|c|}
\hline \multirow[b]{2}{*}{ Item } & \multicolumn{2}{|c|}{ Procedure; cost (\$Can) } & \multirow[b]{2}{*}{ Data source } \\
\hline & TURP & PVP & \\
\hline \multicolumn{4}{|l|}{ Preoperative } \\
\hline Physical examination & Equal & Equal & Alberta SoMB \\
\hline $\begin{array}{l}\text { Diagnostic tests } \\
\text { (blood, urinalysis, etc.) }\end{array}$ & Equal & Equal & $\begin{array}{l}\text { Health costing in Alberta } \\
2005 \text { Annual Report }\end{array}$ \\
\hline \multicolumn{4}{|l|}{ Operative } \\
\hline \multicolumn{4}{|l|}{ Personnel } \\
\hline Circulating nurse & Equal & Equal & \\
\hline Scrub nurse & Equal & Equal & \\
\hline Urologist & Equal & Equal & Alberta SoMB \\
\hline Anesthetist & Equal & Equal & Alberta SoMB \\
\hline \multicolumn{4}{|l|}{ Consumables } \\
\hline Fibre & Lower (0.00) & Higher (650.00) & $\begin{array}{l}\text { Ontario Health Technology } \\
\text { Advisory Committee }\end{array}$ \\
\hline Loop & Higher (100.00) & Lower (0.00) & $\begin{array}{l}\text { E. Woods urologist, } \\
\text { Scarborough General } \\
\text { Hospital, personal } \\
\text { communication: } 2006\end{array}$ \\
\hline Capital (equipment) & Lower (0.00) & Higher $(27.00)^{*}$ & \\
\hline \multicolumn{4}{|l|}{ Postoperative } \\
\hline \multicolumn{4}{|l|}{ Days of hospitalization } \\
\hline Step-down unit & Lower (0.00) & $\begin{array}{l}\text { Higher } \\
\text { (unknown) }\end{array}$ & \\
\hline $\begin{array}{l}\text { General inpatient } \\
\text { ward or unit }(2 \mathrm{~d})\end{array}$ & $\begin{array}{l}\text { Higher } \\
\text { (unknown) }\end{array}$ & Lower (0.00) & \\
\hline $\begin{array}{l}\text { Treatment of } \\
\text { complications or } \\
\text { adverse events }\end{array}$ & Equal & Equal & \\
\hline \multicolumn{4}{|l|}{ Postdischarge } \\
\hline $\begin{array}{l}\text { Treatment of } \\
\text { complications or } \\
\text { adverse events }\end{array}$ & Equal & Equal & Part 2 of this report \\
\hline Retreatment & Equal & Equal & Part 2 of this report \\
\hline
\end{tabular}


evaluated, PVP appears to be as efficacious as TURP. Despite limited economic evidence, findings across all economic studies suggest that PVP is less costly than TURP. It could, therefore, offer an attractive alternative to payers. Further, PVP appears to involve a shorter learning curve relative to other laser approaches, which may enable surgeons to adopt the technology more readily. ${ }^{\prime}$

In April 2007, the next generation PVP system, the 120 W GreenLight HPS received regulatory approval from Health Canada, making it commercially available. ${ }^{31}$ Recent laboratory testing and reports of early clinical experiences in the United States have suggested that the rate of tissue removal with the GreenLight HPS is significantly increased. ${ }^{32}$ However, this requires validation with larger study populations and longer follow-up periods.

From the *School of Public Health, University of Alberta, Edmonton, Alta., the †Royal Alexandra Hospital, Edmonton, Alta., and the łDivision of Urology, University of Alberta, Edmonton, Alta..

This article has been peer reviewed.

Competing interests: None declared.

\section{References}

1. Kuntz RM. Current role of lasers in the treatment of benign prostatic hyperplasia. Eur Urol 2006;49:961-9.

2. Te AE. Current state of the art photoselective vaporization prostatectomy: laser therapy for benign prostatic hyperplasia. Prostate Cancer Prostatic Dis 2007; 10:S2-5.

3. Kirby RS. Greenlight photoselective vaporization of the prostate. Prostate Cancer Prostatic Dis 2007;10:S1.

4. Norman RW, et al. Prostate-related symptoms in Canadian men 50 years of age or older: prevalence and relationships among symptoms. Br I Urol 1994;74:542-50.

5. DiSantostefano RL, Biddle AK, Lavelle JP. An evaluation of the economic and patientrelated consequences of treatments for benign prostatic hyperplasia. BJU Int 2006;97:1007-16.

6. Cochrane Collaboration. Cochrane handbook for systematic reviews of interventions 4.2.6. Ottawa (ON): Cochrane Collaboration; 2006. Available: www.cochrane.org /resources/handbook/Handbook4.2.6Sep2006.pdf (accessed 2006 0ct 4).

7. Cohen J. A coefficient of agreement for nominal scales. Educ Psychol Meas 1960;20: $37-46$.

8. Egger M, Smith GD, Altman DG. Systematic reviews in health care: meta-analysis in context. London (UK): BMJ Publishing Group; 2001

9. Centre for Evidence-Based Medicine. Levels of evidence and grades of recommendation. Oxford (UK): Oxford Centre for Evidence-Based Medicine; 2001. Available: www.cebm.net/levels_of_evidence.asp\#notes (accessed 2006 0ct 4).

10. Bachmann A. Photoselective vaporization (PVP) versus transurethral resection of the prostate (TURP): a prospective bi-centre study of perioperative morbidity and early functional outcome. Eur Urol 2005;48:965-72.

11. Bouchier-Hayes DM. Photoselective vaporization of the prostate - towards a new standard. Prostate Cancer Prostatic Dis 2007;10:S10-4.
12. Hai MA, Malek RS. Photoselective vaporization of the prostate: initial experience with a new $80 \mathrm{~W}$ KTP laser for the treatment of benign prostatic hyperplasia. J Endourol 2003; 14:93-6.

13. Mattioli M, Cremona F, Pozzoni F. Photoselective laser vaporization of the prostate (PVP) for treatment of benign prostatic hyperplasia (BPH). J Endourol 2003;17 (Suppl 1):A318.

14. Sandhu JS, Ng C, Vanderbrink BA, et al. High-power potassium-titanyl-phosphate photoselective laser vaporization of prostate treatment of benign prostatic hyperplasia in men with large prostates. J Urol 2004;64:1155-8.

15. Te AE, Malloy TR, Stein BS, et al. Photoselective vaporization of the prostate for the treatment of benign prostatic hyperplasia: 12-month results from the first United States multicenter prospective trial. J Urol 2004;172:1404-8.

16. Barber N, Zhu G, Donohue I, et al. Day case high-power KTP laser vaporization of the prostate - initial experience. Eur Urol 2004;2(Suppl 3):145.

17. Fu WJ, Hong BF, Yang Y, et al. Photoselective vaporization of the prostate in the treatment of benign prostatic hyperplasia. Chin Med J (Engl) 2005;118:1610-4.

18. Park MS, Ha T. The safety and short-term efficacy of photo selective vaporization of the prostate with $80 \mathrm{~W}$ KTP laser for the treatment of benign prostatic hyperplasia. Eur Urol 2005;3(Suppl 4):255.

19. Sarica K, Alkan E, Luleci H, et al. Photoselective vaporization of the enlarged prostate with KTP laser: long-term results in 240 patients. J Endourol 2005; 19:1199-202.

20. Volkan T, Ihsan TA, Yilmaz 0, et al. Short term outcomes of high power (80W) potassium-titanyl-phosphate laser vaporization of the prostate. Eur Urol 2005;48:608-13.

21. Han E, Black L, Lavelle J. BPH-related surgical procedures in incontinent males with BPH. Program and abstracts of the American Urological Association 2006 Annual Meeting, May 20-25, 2006; Atlanta, Georgia. Abstract 1426.

22. Monoski MA. Urodynamic predictors of outcomes with photoselective laser vaporization prostatectomy in patients with benign prostatic hyperplasia and preoperative retention. Urol 2006;68:312-7.

23. Ruszat $R$, Wyler $S$, Seifert $H H$, et al. Photoselective vaporization of the prostate: subgroup analysis of men with refractory urinary retention. Eur Urol 2006;50:1040-9.

24. American Urological Association. AUA guideline on management of benign prostatic hyperplasia. Chapter 1: diagnosis and treatment recommendations. J Urol 2003; 170:530-47.

25. Rassweiler J, Teber D, Kuntz R, et al. Complications of transurethral resection of the prostate (TURP): Incidence, management, and prevention. Eur Urol 2006;50:969-79.

26. Ruszat $R$, Wyler $S$, Forster $T$, et al. Safety and effectiveness of photoselective vaporization of the prostate (PVP) in patients on ongoing oral anticoagulation. Eur Urol 2007;51:1031-41.

27. Stovsky MD, Griffiths RI, Duff SB. A clinical outcomes and cost analysis comparing photoselective vaporization of the prostate to alternative minimally invasive therapies and transurethral prostate resection for the treatment of benign prostatic hyperplasia. J Urol 2006;176:1500-6.

28. Ruszat R, Sukser T, Scifert HH, et al. Photoselective vaporization (PVP) versus transurethral electroresection of the prostate (TURP); a comparative cost analysis. EAU Congress Paris Abstract № 9996. Eur Urol Suppl 2006:5:271.

29. Medical Advisory Secretariat. Energy delivery systems for treatment of benign prostatic hyperplasia. Toronto (ON): Ontario Ministry of Health and Long Term Care; 2006.

30. Alberta Health and Wellness. Inpatient database 1999-2005. Edmonton (AB): Alberta Health and Wellness; 2006.

31. Therapeutic Products Directorate Medical Devices Bureau. Medical devices active licence listing. Ottawa (ON): Health Canada; 2006. Available: http://cpe001321 lb4c6dcm0014e88ee7a4.cpe.net.cable.rogers.com/mdall/ (accessed 2007 May 10).

32. Te AE. The next generation in laser treatments and the role of the Greenlight HighPerformance System Laser. Rev Urol 2006;8(Suppl 3):S24-30.

Correspondence: Dr. Devidas Menon, Director, Health Policy and Management Stream, Professor, School of Public Health, University of Alberta, 13-103 Clinical Sciences Building, University of Alberta, Edmonton AB T6G 263; menon@ualberta.ca 